Alma Mater Studiorum - Università di Bologna DEPARTMENT OF ECONOMICS

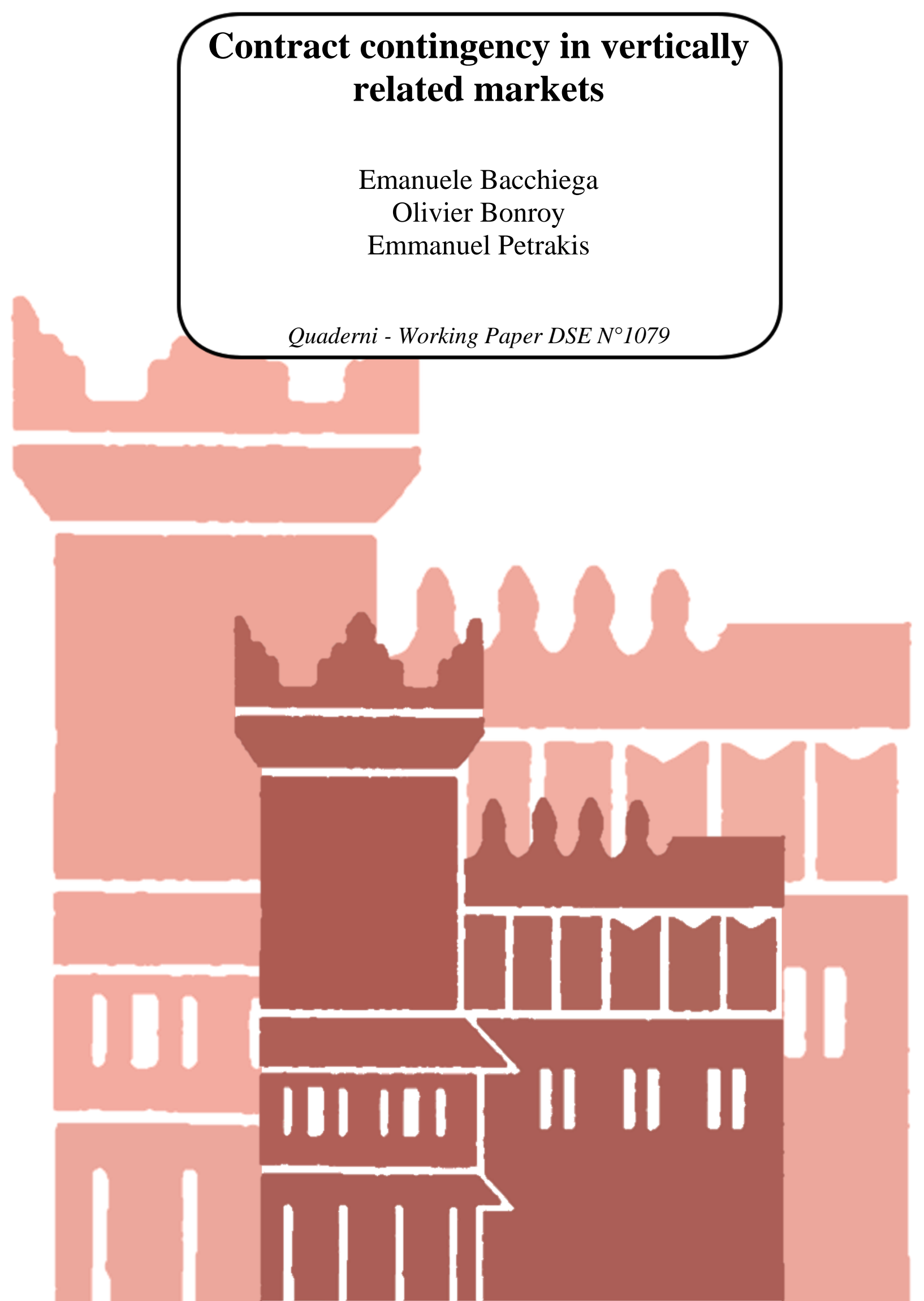




\title{
Contract contingency in vertically related markets*
}

\author{
Emanuele BACCHIEGA ${ }^{\dagger 1}$, Olivier BONROY ${ }^{\ddagger 2}$, and Emmanuel PETRAKIS ${ }^{\S 3}$ \\ ${ }^{1}$ Dipartimento di Scienze Economiche, Alma Mater Studiorum - Università di Bologna, Italy. \\ ${ }^{2}$ INRA, Université Grenoble Alpes, UMR 1215 GAEL, 38000 Grenoble, France. \\ ${ }^{3}$ Department of Economics, University of Crete, Rethymnon 74100, Greece.
}

September 29, 2016

\begin{abstract}
We study the optimal contract choice of an upstream monopolist producing an essential input that may sell to two vertically differentiated downstream firms. The upstream supplier can offer an exclusive contract to one of the firms or non-exclusive contracts to both firms. Each of the latter can be made contingent or not on the breakdown of the negotiations between the upstream supplier and the rival downstream firm. The distribution of bargaining power during the contract terms negotiations is the main driving force of the monopolist's choices. A powerful supplier always opts for an exclusive contract. By contrast, a weaker supplier offers non-exclusive contracts and makes each of them contingent or non-contingent such as to guarantee the most favorable outside option in its negotiations. Our main results hold under an horizontally differentiated downstream market too.
\end{abstract}

Keywords: Vertical relationships, exclusive vs. non-exclusive relationships, contract contingency, two-part tariff, product differentiation.

JEL classification: D43, L13, L14.

\footnotetext{
${ }^{*}$ We wish to thank Tommaso Valletti and Christian Wey for very useful comments and discussion and the audiences at XXXV Jornadas de Economía Industrial, Alicante 2015, $5^{\text {th }}$ EIEF-Unibo-Bocconi IGIER Workshop on Industrial Organization, Rome 2015 and CORE@50 conference, Louvain-la-Neuve, 2016. The usual disclaimer applies.

${ }^{\dagger}$ Corresponding author 凶emanuele. bacchiega@unibo.it

${ }^{\ddagger} \bowtie$ olivier.bonroy@inra.fr

${ }^{\S}$ petrakis@uoc.gr
} 


\section{Introduction}

The bulk of final products in the market has passed through various production stages. Vertical relations, and in particular vertical contracting, is thus of crucial importance for the final good prices, the profitability of firms along the vertical supply chain, the consumer surplus and the social welfare. Vertical contracting refers not only to the type of contracts used in the trading between upstream and downstream firms, but also to the process via which the specific contractual terms are determined. There is a variety of contract types used in the real world. In some industries firms use simple linear wholesale price contracts in their trading, yet in others the contract types are more complicated. ${ }^{1}$ In addition, there is strong evidence that the trading terms of these contracts are negotiated among upstream and downstream firms. ${ }^{2}$ This is mainly due to the recently observed increased concentration in many downstream sectors that has transformed downstream firms to powerful actors. ${ }^{3}$

In this paper we investigate the optimal contact choices of an upstream monopolist that may sell an essential input to downstream firms that produce vertically differentiated products. Once the contracts have been selected, their terms are negotiated between the upstream supplier and the downstream firm(s). Assuming that contracts take the form of two-part tariffs, we inquire into the following issues. Does the upstream supplier have incentives to foreclose one of the downstream firms by offering an exclusive contract to the other firm? And if so, the foreclosed firm will be the high- or the low-quality one? When the upstream firm offers non-exclusive contracts to both downstream firms, what will be the specific type of these contracts? Under what conditions, will it offer a contingent contract that allows renegotiation of contract terms with one downstream firm in case of breakdown in the negotiations with the other one ${ }^{4}$ Or when will it offer a non-contingent contract not allowing for such renegotiations? What are the market and societal implications of the upstream monopolist contract configuration selection?

We consider a vertically related industry with an upstream monopolist and (potentially) two downstream firms. The upstream supplier produces an essential input that sells to one or both downstream firms, depending on its decision at the outset of the game to offer an exclusive or two non-exclusive contracts, respectively. The downstream firms are endowed

\footnotetext{
${ }^{1}$ For empirical studies regarding the contract types used see e.g., Villas-Boas (2007), Thanassoulis and Smith (2009) and Bonnet and Dubois (2010). In addition, in the case of grocery retailing anecdotal evidence indicates the use of very complex contracts that avoid double marginalization (see Inderst and Mazzarotto, 2008).

${ }^{2}$ For evidence of bargaining among milk suppliers and supermarkets see Thanassoulis and Smith (2009). In addition, there is evidence that large retailers, such as Wal-Mart bargain with product suppliers, large book retailers, such as Barnes \& Noble, bargain with publishers, large tour operators bargain with hotels.

${ }^{3}$ The increase in downstream concentration has been noted in a number of policy reports (see e.g. European Commission, 1999, OECD, 1999, and FTC, 2001).

${ }^{4}$ According to (Bazerman and Gillespie, 1998, p. 155), "the terms of a contingent contract are not finalized until the uncertain event in question-the contingency-takes place."
} 
with different technologies that allow the production of different output qualities using the same input (see Gabszewicz and Thisse, 1979; Shaked and Sutton, 1983). ${ }^{5}$ If the upstream supplier chooses to offer contracts to both downstream firms, it must also decide whether each of them is contingent or non-contingent. A contingent contract is more flexible and allows negotiating parties to set different contractual terms in case of agreement and in case of disagreement in the rival bargaining pair. This flexibility is absent under a non-contingent contract.

We study a three-stage game with observable actions. In the first stage, the upstream monopolist decides to offer an exclusive contract or two non-exclusive ones. In the former case, it also decides to which of the downstream firms to make the offer. In the latter case, it also decides the configuration of contracts to be offered, i.e., two contingent, two non-contingent, or mixed (one contingent and another non-contingent) contracts. In legal terms, this can be materialized by using a letter of intent wherewith the upstream firm sets out its intentions about the number and type of contractual relations to enter. ${ }^{6}$ In the second stage, negotiations over contract terms take place between the upstream monopolist and the downstream firm(s). In case of non-exclusive contracts, these negotiations take place simultaneously and separately between the upstream supplier and each of the downstream firms. In the last stage, under non-exclusive contracts, the downstream firms compete in the market by selecting their prices or their quantities; under an exclusive contract, the downstream monopolist sets its price.

As the alternative types of non-exclusive contracts are central in our analysis, a discussion in detail of their features will be of great help for the sequel. A non-exclusive contract signed between the upstream supplier and a downstream firm can be of two types: contingent and non-contingent. A contingent contract contains specific terms in the event of a breakdown in the negotiations in the rival bargaining pair. An immediate consequence is that the outside options for the negotiating firms fully internalize the implications of the negotiation failure in the rival pair. By contrast, a non-contingent contract does not allow for renegotiation of contract terms in case of a breakdown in the negotiations in the rival bargaining pair. As a consequence, the outside options for the negotiating firms are determined by their equilibrium contractual terms. Therefore, the crucial difference between the two types of non-exclusive contracts lies on the outside options that are attributed to negotiating parties under each of them (see e.g., Milliou and Petrakis (2007)).

\footnotetext{
${ }^{5}$ For instance, one of the downstream firms has a proprietary technology that allows it to increase at no cost the quality of its good.

${ }^{6}$ With a letter of intent, a party sets forth its intention to sign a contract in the circumstances reported in the letter. It is worth noticing that "A letter of intent is not itself a formal contract but certain of its provisions (e.g. concerning payment for any work completed) may nevertheless be enforceable. Letters of intent are widely used in the UK construction industry, where their usual purpose is to encourage a contractor to begin work on a time-sensitive project before legal formalities have been completed. Recent case law suggests that the courts are increasingly willing to find that a letter of intent constitutes a binding contract, provided that all necessary elements of a contract are present [... ]" Law (2016).
} 
Our analysis highlights the role of the bargaining power distribution between the upstream supplier and each of the downstream firms for the optimal selection of contracts. In particular, when the upstream supplier is quite powerful, it offers an exclusive contract to the high quality downstream firm, whereas it selects two non-exclusive contracts when its bargaining power is not too high. The upstream supplier faces the following trade-off when selecting between an exclusive and two non-exclusive contracts. Under an exclusive contract, competition downstream is absent altogether, therefore, under two-part tariff contracts, the vertically integrated structure outcome is obtained. Yet, the upstream supplier's outside option (i.e., its profits when the negotiations with the downstream firm break down) is nil in this case. This entails that its share of the vertically integrated entity's profits is proportional to the upstream bargaining power. The lower the latter, the smaller the profit that the upstream supplier is able to extract. By contrast, with non-exclusive contracts that are negotiated simultaneously and separately, competition downstream erodes part of the aggregate producer surplus (O'Brien and Shaffer, 1992). Yet, with non-exclusive contracts, the upstream supplier may have a stronger bargaining position, i.e., it may enjoy positive outside options in its negotiations with the downstream firms, for any level of its bargaining power. A powerful upstream firm can extract most of the vertically integrated structure's profit and prefers, thus, to avoid creating downstream competition that reduces the aggregate producers surplus. In addition, as the production of the high-quality good generates a higher surplus, the upstream opts to offer the contract to the high quality downstream firm. In this way, the upstream supplier forecloses the low-quality firm.

As the upstream supplier becomes less powerful, it can extract a lower share of the vertically integrated structure. Nonetheless, by offering two non-exclusive contracts, the upstream supplier can enjoy a stronger bargaining position through the creation of outside options in its negotiations with the downstream firms (of course, this comes at the cost of reducing the aggregate producer surplus due to downstream competition). In particular, for "intermediate" levels of bargaining power, the upstream firm opts for two non-exclusive, contingent contracts, whereas for even lower values of it, it offers a non-contingent contract to the high-quality downstream firm and a contingent contract to the low-quality one. Finally, an upstream supplier with quite low bargaining power opts for two non-exclusive, non-contingent contracts. As discussed above, a contingent contract is more flexible in the sense that it allows a negotiating pair to specify different contract terms in case of agreement and in case of disagreement in the rival bargaining pair. This translates into higher outside options for the upstream supplier under contingent than under non-contingent contracts, but only if its bargaining power is not too low. The opposite holds for lower values of the upstream bargaining power, in which case the upstream supplier opts for one or two non-contingent contracts. In the mixed contract configuration, the non-contingent contract is always offered to the high-quality firm. In this 
way, the upstream supplier enjoys the largest outside options once again. Finally, our analysis reveals that the degree of vertical product differentiation affects the upstream supplier's choice of the configuration of non-exclusive contracts. In particular, as the goods become less differentiated, the range of parameters for which the upstream supplier offers mixed contracts shrinks; moreover, that non-contingent contracts are more often selected when the product differentiation takes intermediate values.

Interestingly, the fixed fees of the equilibrium non-exclusive contracts are sometimes negative, i.e., the upstream supplier pays "slotting allowances" (Shaffer, 1991; Marx and Shaffer, 2010) to one or both downstream firms. This is always true when the upstream supplier offers two non-contingent contracts. It is also true under contingent and mixed contracts as long as the upstream bargaining power is low enough. Surprisingly, under some circumstances, the contract offered to the low-quality firm generates an overall loss for the upstream supplier. This loss is however covered by a substantial gain for the upstream supplier that so enjoys a stronger bargaining position vis-à-vis the high-quality downstream firm.

Our main findings carry on, to a major extent, when downstream firms compete in quantities, instead of prices. There are, however, two points of departure. First, two non-exclusive, non-contingent contracts are never observed in equilibrium. This is because the outside options they imply for the upstream supplier are lower than under contingent contracts, confirming thus the intuition of the price setting market. And second, the degree of vertical product differentiation now plays a crucial role. Mixed contracts are never observed in equilibrium when the goods are not differentiated enough. Moreover, an exclusive contract to the high-quality firm is selected by the upstream supplier even if its bargaining power is low, provided that the goods are not too differentiated.

Finally, we show that our main findings are not specific to the vertical product differentiation setup, but hold also in an horizontally differentiated model in which a representative consumer has a Bowley (1924), Spence (1976), Dixit (1979) utility function. The main departing point in this case is that exclusive contracts are observed in equilibrium only if the goods are close substitutes. When the goods are poor substitutes, the upstream supplier prefers to strengthen its bargaining position by offering non-exclusive, contingent contracts to both downstream firms.

Our paper connects to several strands of the literature. First, it contributes to the literature on vertical contracting. A main theme within this literature is the commitment problem that arises for an upstream monopolist when it trades with multiple competing downstream firms (see, e.g. Horn and Wolinsky, 1988; O'Brien and Shaffer, 1992; McAfee and Schwartz, 1994, 1995; Rey and Vergé, 2004). These papers, however, do not consider the optimal choice of contracts offered by the upstream supplier to the downstream firms. Our paper undertakes this task and highlights the differential impact of contingent and non-contingent, non-exclusive 
contracts on the severity of the upstream monopolist's commitment problem. Based on that, we are able to identify conditions under which an upstream monopolist offers an exclusive or two non-exclusive contracts, and within the non-exclusive contracts when it offers contingent, non-contingent and mixed contracts to the downstream firms.

It also contributes to the literature on the effects of countervailing buyer power (see, e.g. Inderst and Wey, 2003, 2007). More closely related to our analysis is the paper by Milliou and Petrakis (2007). Their focus is on merger incentives when upstream supplier(s) choose(s) optimally the contracts to be offered to the downstream firms. They consider the choice between wholesale price and two-part tariff contracts, assuming though that these contracts are non-contingent. By contrast, we consider two-part tariff contracts and highlight that the contingency or non-contingency of their terms is crucial for the selection of contracts by the upstream monopolist. As in Milliou and Petrakis (2007), upstream and downstream firms negotiate over contract terms, with the bargaining power distribution among negotiating parties to be exogenously given. ${ }^{7}$ Further, Miklós-Thal et al. (2011) consider powerful downstream retailers offering take-it-or-leave-it contracts to an upstream supplier that may be contingent on an exclusive relationship, and show that contingency may lead to the replication of monopoly outcomes. From another standpoint, Iozzi and Valletti (2014) delve into the role of the observability of negotiations breakdown in determining the outside option of an upstream supplier facing multiple downstream retailers, when negotiations are determined through the generalized Nash bargaining solution.

Our paper also contributes to the literature on vertical foreclosure. Hart and Tirole (1990), O'Brien and Shaffer (1992), and McAfee and Schwartz (1994) show that under secret contracting, exclusive agreements or vertical integration can help a dominant supplier to reestablish its market power. Rey and Tirole (2007) provide an excellent overview on vertical foreclosure and stress the anticompetitive motives for upstream firms to use exclusive agreements and vertical mergers in order to foreclose downstream firms. The received literature, however, does not consider vertically differentiated industries. In line with this literature, we show that an upstream monopolist opts for an exclusive contract with the high-quality downstream firm, thus foreclosing the low-quality one, in order to restore its market power. Nevertheless, this is optimal for the supplier only when its bargaining power is sufficiently high. Otherwise, the upstream supplier has incentive to keep both competing downstream firms in the market.

Finally, our paper contributes to the debate regarding the choice of a firm to offer or not a pooling or a separating menu in markets of vertical product differentiation, see Acharyya (1998), Bacchiega et al. (2013) and Chambolle and Villas-Boas (2015). These papers consider either a monopolist selling to heterogeneous consumers different qualities of a good or two

\footnotetext{
${ }^{7}$ In a different vein, Alipranti et al (2014), assuming negotiations over two-part tariff non-contingent contracts between an upstream supplier and two downstream firms, compare Cournot and Bertrand downstream competition.
} 
upstream suppliers offering different qualities of products to a monopolist retailer or to two competing retailers. In contrast, we assume that the downstream market is vertically differentiated, whereas the essential input produced by the upstream supplier is homogeneous. In line with this literature, we identify circumstances under which the upstream monopolist offers the same or different types of non-exclusive contracts to both downstream firms. In particular, when the upstream bargaining power is relatively low (but not too low), the supplier opts for a contingent contract to the low-quality downstream firm and a non-contingent contract to the high-quality one. ${ }^{8}$

The remainder of the paper is organized as follows. Section 2 presents the model, Section 3 explores the various contractual choices and Section 4 performs the contractual choice equilibrium analysis. Section 5 discusses the equilibrium outcomes. Section 6 explores the robustness of our results. Finally, Section 7 provides concluding remarks.

\section{The model}

\subsection{Firms and market structure}

Consider an upstream monopolist, denoted by $\mathcal{U}$, producing at no cost an essential input that may sell to two downstream firms. Downstream firms use this input to produce, on a one-to-one basis, a final good. Besides the input costs, downstream firms incur no additional production costs. One of these firms has a proprietary technology that allows it to increase at no cost the quality of its good. Denote the latter "high-quality good" and the downstream producer "high-quality firm", $\mathcal{D}_{h}$. The other downstream firm, the "low-quality firm", $\mathcal{D}_{l}$, does not dispose such a technology and thus produces the "basic" version of the good, i.e., the "low-quality good". The upstream monopolist decides whether to offer an exclusive supply contract and if so, to which of the downstream firms to make the offer. Under an exclusive contract the upstream monopolist commits to trade with one downstream firm alone, therefore the downstream market is a monopoly.

By contrast, if the upstream supplier chooses to sign non-exclusive contracts, it trades with both downstream firms and thus the downstream market is a vertically differentiated duopoly. Non-exclusive contracts can be of two types: non-contingent and contingent. Contingent contracts allow bargaining partners $\mathcal{U}$ and $\mathcal{D}_{i}$ to renegotiate the contract in case of disagreement between $\mathcal{U}$ and $\mathcal{D}_{j}$. Under non-contingent contracts, the bargaining partners should stick to their negotiated contract terms under all contingencies. The upstream supplier

\footnotetext{
${ }^{8}$ From a broader perspective, our viewpoint of contract contingency as an instrument to affect the bargaining position of the negotiating parties is alternative to those suggested in the economic literature, in which contract contingency is seen as a tool to reduce the incompleteness of contracts (see, e.g. Hart and Holmström, 1987), and in the management literature, in which it is seen as a tool to share risks (Byialogorsky and Gerstner, 2004).
} 
decides which type of non-exclusive contract to offer to each downstream firm. ${ }^{9}$

Vertical contracts are non-linear and in particular, take the form of two-part tariffs, and are bargained between the upstream monopolist and the downstream firm(s). During the contract negotiations, the bargaining power of $\mathcal{U}$ and $\mathcal{D}_{i}, i=h, l$, are $\mu$ and $1-\mu, 0 \leq \mu \leq 1$, respectively.

\subsection{Demand}

A continuum of heterogeneous consumers of unit mass is uniformly distributed with unitary density over the interval $[0,1]$. A consumer $\theta, \theta \in[0,1]$, is characterized by the indirect utility function

$$
U\left(\theta, u_{i}\right)= \begin{cases}\theta u_{i}-p_{i} & \text { when buying one unit of good } i \\ 0 & \text { otherwise }\end{cases}
$$

where $u_{i}$ is the (given) quality level of good $i$ and $p_{i}$ is its price. Remember that $u_{i}$ only depends upon the downstream firm selling the good.

Under an exclusive contract, there is only one good available in the market. Using the standard marginal consumer approach, its demand is

$$
D_{m}\left(p_{m}\right)=1-\frac{p_{m}}{u_{i}}
$$

where the subscript $m$ indicates "downstream monopoly" and $i=h, l$, depending on which downstream firm the supply contract has been signed with. In this case, the consumer surplus is

$$
C S_{m}\left(p_{m}\right)=\int_{\frac{p_{m}}{u_{i}}}^{1}\left(\theta u_{i}-p_{m}\right) d \theta
$$

Under non-exclusive contracts, two goods are available in the market. Using again the standard marginal consumer approach, ${ }^{10}$ their demands are

$$
D_{h}\left(p_{h}, p_{l}\right)=1-\frac{p_{h}-p_{l}}{u_{h}-u_{l}}, \quad D_{l}\left(p_{h}, p_{l}\right)=\frac{p_{h}-p_{l}}{u_{h}-u_{l}}-\frac{p_{l}}{u_{l}}
$$

with $u_{h}>u_{l}>0$ being the quality levels of the two goods. The consumers surplus is

\footnotetext{
${ }^{9}$ This may be materialized by writing a letter of intent which contains the number and - in case of non exclusivity - the type of contractual relationships which the upstream supplier is willing to enter. Contracts may then be made contingent by including in such letters the appropriate conditions precedent.

${ }^{10}$ The consumer which is indifferent between buying the high or the low quality good is determined by $\theta_{h l} u_{h}-p_{h}=\theta_{h l} u_{l}-p_{l}$; and the consumer which is indifferent between buying the low quality good or not buying at all is determined by $\theta_{l 0} u_{l}-p_{l}=0$.
} 


$$
C S\left(p_{h}, p_{l}\right) \equiv \int_{\frac{p_{l}}{u_{l}}}^{\frac{p_{h}-p_{l}}{u_{h}-u_{l}}}\left(\theta u_{l}-p_{l}\right) d \theta+\int_{\frac{p_{h}-p_{l}}{u_{h}-u_{l}}}^{1}\left(\theta u_{h}-p_{h}\right) d \theta
$$

\section{$2.3 \quad$ Timing}

We consider a three-stage game with observable actions. At the first stage, the upstream supplier decides whether to offer an exclusive contract, and if so, to which of the downstream firms. If, instead, it decides to offer non-exclusive contracts, the upstream supplier selects also whether to make each of these contracts contingent or non-contingent. In addition, it decides whether or not to offer the same type of contract to both downstream firms. In case that the two contracts differ, the upstream supplier decides whether to offer, e.g., the contingent contract to the low or the high quality downstream firm. At the second stage, the upstream monopolist and the downstream firm(s) bargain (simultaneously) over two-part tariff contract(s). Finally, the downstream firm(s) set price(s) in the market. ${ }^{11}$

As is standard, we use subgame perfection to solve our three-stage game. Moreover, we invoke the Nash equilibrium of simultaneous generalized Nash bargaining problems to solve for the simultaneous contract terms negotiations between $\mathcal{U}$ and each of $\mathcal{D}_{i}, i=h, l$, under non-exclusive contracts. Under exclusive contracts, the generalized Nash bargaining solution is also used to solve for the contract terms negotiations between $\mathcal{U}$ and one of the downstream firms.

\section{Contract terms and market outcomes}

In the next subsections, we analyze the subgames in which the upstream monopolist offers respectively an exclusive contract or two non-exclusive contracts. In the latter case, we distinguish between the symmetric cases in which both downstream firms are offered either non-contingent or contingent contracts and the mixed cases of one downstream firm being offered a contingent and the other a non-contingent contract.

\subsection{Exclusive contract}

Under an exclusive contract, the downstream firm to which the upstream supplier offers the contract becomes a monopolist in the final good market. Let $T_{m} \equiv\left(w_{m}, t_{m}\right)$ be the twopart tariff contract signed by the upstream and the downstream firm, where $w_{m}$ is the input price and $t_{m}$ is the fixed fee, with $m$ standing for downstream monopoly. The profits of the

\footnotetext{
${ }^{11}$ Section 6 deals with the alternative case in which firms compete in quantities.
} 
upstream and downstream firms are, respectively

$$
\Pi_{m}\left(p_{m}, T_{m}\right)=D_{m}\left(p_{m}\right) w_{m}+t_{m}, \quad \pi_{m}\left(p_{m}, T_{m}\right)=D_{m}\left(p_{m}\right)\left(p_{m}-w_{m}\right)-t_{m}
$$

In the last stage, the downstream firm maximizes its profit by setting $\hat{p}_{m}\left(w_{m}\right)=\frac{u_{i}+w_{m}}{2}$. Substituting the latter into (6), we obtain downstream and upstream equilibrium profits

$$
\hat{\Pi}_{m}\left(T_{m}\right)=\frac{\left(u_{i}-w_{m}\right) w_{m}}{2 u_{i}}+t_{m}
$$

and

$$
\hat{\pi}_{m}\left(T_{m}\right)=\frac{\left(u_{i}-w_{m}\right)^{2}}{4 u_{i}}-t_{m} .
$$

Turning to the second stage, the upstream supplier and the downstream firm negotiate over the contract terms. As the upstream supplier is committed to offer an exclusive contract, in case of failure to reach an agreement neither the upstream nor the downstream firm operate in the market; hence both firms' outside options are nil. The generalized Nash product is, therefore,

$$
N P_{m}\left(T_{m}\right)=\hat{\Pi}_{m}\left(T_{m}\right)^{\mu} \hat{\pi}_{m}\left(T_{m}\right)^{1-\mu} .
$$

The maximization of (9) with respect to $w_{m}$ and $t_{m}$ yields $w_{m}^{*}=0$ and $t_{m}^{*}=\frac{u_{i}}{4} \mu$. As standard in this case, the two-part tariff contract is set in such a way as to maximize the joint profit of the vertical chain. This is achieved by setting the input price equal to the upstream marginal cost and by apportioning the maximum joint profit between the upstream and downstream firm via the fixed fee, according to their respective bargaining powers. Therefore, the profits accruing to the upstream firm are $\frac{u_{i}}{4} \mu$ and are increasing in the quality of the good $u_{i}$. As a consequence, the upstream supplier will offer the exclusive contract to the high quality downstream firm. The following Lemma summarizes our findings.

Lemma 1. If the upstream supplier opts for an exclusive contract, it offers it to the high quality downstream firm. The equilibrium contract terms are $w_{m}^{*}=0$ and $t_{m}^{*}=\frac{u_{h}}{4} \mu$. The

equilibrium price is $p_{m}^{*}=\frac{u_{h}}{2}$, the equilibrium demand is $D_{m}^{*}=\frac{1}{2}$, and the equilibrium profits of the upstream and downstream firms are, respectively, $\Pi_{m}^{*}=\frac{u_{h}}{4} \mu$ and $\pi_{m}^{*}=\frac{u_{h}}{4}(1-\mu)$. Moreover, the consumer surplus is $C S_{m}^{*}=\frac{u_{h}}{8}$.

\section{$3.2 \quad$ Non-exclusive non-contingent contracts}

We now turn to the case in which the upstream monopolist offers supply contracts to both downstream firms. For the sake of brevity, we will often refer to the contract signed between the upstream supplier and the high (low) quality downstream firm as "the high (low) quality contract". We assume that negotiations over contract terms within each $\left(\mathcal{U}, \mathcal{D}_{i}\right)$ pair occur 
simultaneously and separately, and that the contracts are interim observable, i.e., once the contracts have been signed, their terms become known to all the parties (see e.g., McAfee and Schwartz, 1995). It is well-known that in such a situation, the vertical relations between the upstream supplier and each of the downstream firms are affected by opportunism. In particular, within each $\left(\mathcal{U}, \mathcal{D}_{i}\right)$ negotiating pair, an incentive exists to secretly renegotiate the contract terms at their own advantage and at the expense of the rival downstream firm $j$ $(i, j=h, l, i \neq j)$. One of the consequences is that multiple equilibria may arise in this case. To deal with this issue and obtain a unique outcome, we invoke pairwise proofness in the equilibrium contracts (O'Brien and Shaffer, 1992; Milliou and Petrakis, 2007; Alipranti et al., 2014).

In this subsection, we consider that the upstream supplier offers non-contingent contracts to both downstream firms, while the case of contingent and mixed contracts will be analyzed in the following two subsections. A contract between $\mathcal{U}$ and $\mathcal{D}_{i}$ is non-contingent if its terms remain intact independently whether the $\left(\mathcal{U}, \mathcal{D}_{j}\right)$ negotiating pair reaches or not an agreement. Stated differently, the (out-of-equilibrium) occurrence of breakdown in the negotiations between the upstream supplier and the downstream firm $j$ does not initiate negotiations anew between $\mathcal{U}$ and $\mathcal{D}_{i}$, instead the $\left(\mathcal{U}, \mathcal{D}_{i}\right)$ pair abides with its agreed contract terms. By contrast, a contract is contingent when it specifies different contract terms for the case of agreement and for the case of disagreement in the rival bargaining pair. For a thorough discussion of contract contingency see Milliou and Petrakis (2007).

In the last stage, given the demand system in (4) and the contracts $T_{i} \equiv\left(w_{i}, t_{i}\right)$ signed between the upstream supplier and the downstream firm $i, i=h, l$, the profits of the downstream firm $i$ and the upstream supplier are

$$
\begin{aligned}
\pi_{i}\left(p_{h}, p_{l}, T_{i}\right) & =D_{i}\left(p_{h}, p_{l}\right)\left(p_{i}-w_{i}\right)-t_{i}, \quad i=h, l, \\
\Pi\left(p_{h}, p_{l}, T_{h}, T_{l}\right) & =D_{h}\left(p_{h}, p_{l}\right) w_{h}+D_{l}\left(p_{h}, p_{l}\right) w_{l}+t_{h}+t_{l} .
\end{aligned}
$$

Solving the system of equations defined by the first-order conditions $\frac{\partial \pi_{i}(\cdot)}{\partial p_{i}}=0$ and observing that the second-order conditions are satisfied as long as $u_{h}>u_{l}>0$, it is easy to obtain the equilibrium prices

$$
\hat{p}_{h}\left(w_{h}, w_{l}\right)=\frac{u_{h}\left[2\left(u_{h}-u_{l}+w_{h}\right)+w_{l}\right]}{4 u_{h}-u_{l}}, \quad \hat{p}_{l}\left(w_{h}, w_{l}\right)=\frac{u_{l}\left(u_{h}-u_{l}+w_{h}\right)+2 u_{h} w_{l}}{4 u_{h}-u_{l}} .
$$

Substituting (12) into (10) and (11), the equilibrium downstream and upstream profits 
are

$$
\begin{aligned}
\hat{\pi}_{h}\left(T_{h}, w_{l}\right) & =\frac{\left[2 u_{h}^{2}+u_{h}\left(w_{l}-2\left(u_{l}+w_{h}\right)\right)+u_{l} w_{h}\right]^{2}}{\left(u_{h}-u_{l}\right)\left(4 u_{h}-u_{l}\right)^{2}}-t_{h}, \\
\hat{\pi}_{l}\left(T_{l}, w_{h}\right) & =\frac{u_{h}\left[u_{h}\left(u_{l}-2 w_{l}\right)+u_{l}\left(w_{h}+w_{l}-u_{l}\right)\right]^{2}}{u_{l}\left(u_{h}-u_{l}\right)\left(4 u_{h}-u_{l}\right)^{2}}-t_{l}, \\
\hat{\Pi}\left(T_{h}, T_{l}\right) & =\frac{u_{l} \vartheta+u_{h} u_{l} w_{l}\left(u_{h}-u_{l}+2 w_{h}\right)+u_{h} w_{l}^{2}\left(u_{l}-2 u_{h}\right)}{u_{l}\left(u_{h}-u_{l}\right)\left(4 u_{h}-u_{l}\right)}+t_{h}+t_{l},
\end{aligned}
$$

with $\vartheta=\left[w_{h}^{2}\left(u_{l}-2 u_{h}\right)+2 u_{h} w_{h}\left(u_{h}-u_{l}\right)\right]$.

We next turn to the bargaining stage. As noted above, in the case of non-contingent contracts, say, the $\left(\mathcal{U}, \mathcal{D}_{h}\right)$ pair cannot include in their bargaining agenda contract terms that will be executed only in the (out-of-equilibrium) case of negotiations breakdown between $\mathcal{U}$ and $\mathcal{D}_{l}$. This entails that the outside option for the upstream monopolist when bargaining with downstream firm $i$ depends on the equilibrium contract terms signed with firm $j$.

Let $T_{i}^{N} \equiv\left(w_{i}^{N}, t_{i}^{N}\right), i=h, l$, be the equilibrium non-contingent contract signed within the $\left(\mathcal{U}, \mathcal{D}_{i}\right)$ pair. In the bargaining with, say, firm $\mathcal{D}_{h}$, the outside option of the upstream monopolist is the profit it would earn in case of negotiations breakdown with firm $\mathcal{D}_{h}$ itself. Should this occur, the upstream supplier still expects to sign the contract $T_{l}^{N}$ with downstream firm $\mathcal{D}_{l}$, which, however, will be a monopolist in the final good market. The outside option for the upstream monopolist is, therefore, $\hat{\Pi}_{m}\left(T_{l}^{N}\right)$, whereas the outside option for the downstream firm $\mathcal{D}_{h}$ is zero (Similarly, for the bargaining between $\mathcal{U}$ and $\mathcal{D}_{l}$ ). ${ }^{12}$ Accordingly, the generalized Nash products are

$$
\begin{aligned}
N P_{h}^{N}\left(T_{h}, T_{l}^{N}\right) & =\left[\hat{\Pi}\left(T_{h}, T_{l}^{N}\right)-\hat{\Pi}_{m}\left(T_{l}^{N}\right)\right]^{\mu} \hat{\pi}_{h}\left(T_{h}, w_{l}^{N}\right)^{1-\mu}, \\
N P_{l}^{N}\left(T_{h}^{N}, T_{l}\right) & =\left[\hat{\Pi}\left(T_{h}^{N}, T_{l}\right)-\hat{\Pi}_{m}\left(T_{h}^{N}\right)\right]^{\mu} \hat{\pi}_{l}\left(T_{l}, w_{h}^{N}\right)^{1-\mu} .
\end{aligned}
$$

\footnotetext{
${ }^{12}$ Inderst and Wey (2003); de Fontenay and Gans (2005) develop an explicit strategic bargaining game to model the idea that the negotiation between parties can come to a breakdown.
} 
Standard maximization techniques allow us to find the equilibrium non-contingent contracts ${ }^{13}$

$$
\begin{aligned}
T_{h}^{N} & =\left(w_{h}^{N}, t_{h}^{N}\right)=\left(\frac{u_{l}}{4}, \frac{8 \mu u_{h}^{3}-4(1+\mu) u_{h}^{2} u_{l}+2(1-\mu) u_{h} u_{l}^{2}-(1-\mu) u_{l}^{3}}{32 u_{h}^{2}}\right), \\
T_{l}^{N} & =\left(w_{l}^{N}, t_{l}^{N}\right)=\left(\frac{u_{l}^{2}}{4 u_{h}}, \frac{u_{l}\left[2 \mu u_{h}-(3-\mu) u_{l}\right]}{32 u_{h}}\right) .
\end{aligned}
$$

Substituting the above back into prices, demands and profits yields the following result.

Lemma 2. If the upstream supplier offers non-contingent contracts to both downstream firms then the equilibrium contract terms are (18) and (19). The equilibrium prices are $p_{h}^{N}=\frac{2 u_{h}-u_{l}}{4}$ and $p_{l}^{N}=\frac{u_{l}}{4}$, and the equilibrium demands $D_{h}^{N}=\frac{1}{2}$ and $D_{l}^{N}=\frac{1}{4}$. The equilibrium profit of the upstream monopolist is $\Pi^{N}=\frac{8 \mu u_{h}^{3}-2 \mu u_{h}^{2} u_{l}+(1-\mu) u_{h} u_{l}^{2}-(1-\mu) u_{l}^{3}}{32 u_{h}^{2}}$, and those of the downstream firms are $\pi_{h}^{N}=\frac{(1-\mu)\left(2 u_{h}-u_{l}\right)^{2}\left(2 u_{h}+u_{l}\right)}{32 u_{h}^{2}}$ and $\pi_{l}^{N}=\frac{(1-\mu) u_{l}\left(2 u_{h}+u_{l}\right)}{32 u_{h}}$. Finally, the consumer surplus is $C S^{N}=\frac{u_{h}}{8}+\frac{5}{32} u_{l}$.

\subsection{Non-exclusive contingent contracts}

Contingent contracts capture the idea that bargaining pairs can come to a permanent and irrevocable breakdown in their negotiations (see, e.g. Inderst and Wey, 2003; de Fontenay and Gans, 2005). Therefore, a contingent contact between the upstream monopolist and the downstream firm $i$ contains specific terms that will be executed in case that the negotiations between $\mathcal{U}$ and $\mathcal{D}_{j}$ breakdown. In such a case, the downstream firm $i$ becomes a monopolist in the final good market and the upstream supplier's profit is as under exclusive contracts, namely, $\frac{u_{i}}{4} \mu$ (see subsection 3.1). The latter is thus the outside option of the upstream supplier in the bargaining with the downstream firm $i$, while the outside option of the downstream firm is again nil.

As the last stage of the game is unaffected by the contingency or not of the contracts (see subsection 3.2 for last stage equilibrium outcomes), the generalized Nash products are

$$
\begin{aligned}
N P_{h}^{C}\left(T_{h}, T_{l}^{C}\right) & =\left[\hat{\Pi}\left(T_{h}, T_{l}^{C}\right)-\frac{u_{l}}{4} \mu\right]^{\mu} \hat{\pi}_{h}\left(T_{h}, w_{l}^{C}\right)^{1-\mu}, \\
N P_{l}^{C}\left(T_{h}^{C}, T_{l}\right) & =\left[\hat{\Pi}\left(T_{h}^{C}, T_{l}\right)-\frac{u_{h}}{4} \mu\right]^{\mu} \hat{\pi}_{l}\left(T_{l}, w_{h}^{C}\right)^{1-\mu} .
\end{aligned}
$$

where $T_{i}^{C} \equiv\left(w_{i}^{C}, t_{i}^{C}\right), i=h, l$, is the equilibrium contingent contract signed between $\mathcal{U}$ and $\mathcal{D}_{i}$.

\footnotetext{
${ }^{13}$ Maximizing first each generalized Nash product $N P_{i}^{N}(\cdot)$ w.r.t. $t_{i}$, then plugging the solution back into $N P_{i}^{N}(\cdot)$, we end up with an expression proportional to the excess joint profits of the $\left(\mathcal{U}, \mathcal{D}_{i}\right)$ pair. Then maximizing these excess joint profits w.r.t. $w_{i}$ and solving the system of the first order conditions, we obtain the equilibrium contract terms. Second-order conditions are locally satisfied, which, together with the uniqueness of the maximizers, insures the uniqueness of the solution. The detailed (and cumbersome) calculations are available upon request.
} 
Unlike in the case of non-contingent contracts, concavity of the functions (20) and (21) at the critical points identified by the first order conditions (focs) is not always guaranteed. Nevertheless, a sufficient condition that guarantees concavity at the unique solution of the system of the focs is that $\mu \leq \frac{3}{4}$. In fact, if $\frac{3}{4}<\mu \leq 1$, the profit of the low quality downstream firm at the solution of the focs turns out to be negative, thereby violating its participation constraint. Here we will focus on the analysis of the interior solution, relegating that of the corner solution $\left(\frac{3}{4}<\mu \leq 1\right)$ to the Appendix 1. As we will see, offering two contingent contracts in this latter case turns out to be a dominated strategy for the upstream supplier.

Let $\mu \leq \frac{3}{4}$. Using standard maximization techniques, ${ }^{14}$ we obtain the equilibrium contracts

$$
\begin{aligned}
& T_{h}^{C}=\left(w_{h}^{C}, t_{h}^{C}\right)=\left(\frac{u_{l}}{4}, \frac{\left.4 \mu(2-\mu) u_{h}-(3+\mu) u_{l}\right)}{16(2-\mu)}\right) \\
& T_{l}^{C}=\left(w_{l}^{C}, t_{l}^{C}\right)=\left(\frac{u_{l}^{2}}{4 u_{h}}, \frac{u_{l}\left[\left(-1+6 \mu-4 \mu^{2}\right) u_{h}-(2-\mu) u_{l}\right]}{16(2-\mu) u_{h}}\right) .
\end{aligned}
$$

The following Lemma summarizes our findings.

Lemma 3. If the upstream supplier offers contingent contracts to both downstream firms then:

(i) If $\mu \leq \frac{3}{4}$, the equilibrium contract terms are given by (22) and (23). The equilibrium prices are $p_{h}^{C}=\frac{2 u_{h}-u_{l}}{4}, p_{l}^{C}=\frac{u_{l}}{4}$, and the equilibrium demands are $D_{h}^{C}=\frac{1}{2}, D_{l}^{C}=\frac{1}{4}$. The equilibrium profits of the upstream monopolist are $\Pi^{C}=\frac{\mu\left[4 u_{h}-u_{l}+4(1-\mu)\left(u_{h}+u_{l}\right)\right]}{16(2-\mu)}$ and those of the downstream firms are $\pi_{h}^{C}=\frac{(1-\mu)\left[4 u_{h}(2-\mu)-5 u_{l}\right]}{16(2-\mu)}$ and $\pi_{l}^{C}=\frac{u_{l}(1-\mu)(3-4 \mu)}{16(2-\mu)}$. The consumer surplus is $C S^{C}=\frac{u_{h}}{8}+\frac{5}{32} u_{l}$.

(ii) If $\frac{3}{4}<\mu \leq 1$, the upstream supplier should adjust the fixed fee downwards in order to incentivize the low-quality firm to sign the contract. Non exclusive contingent contracts are, however, dominated by an exclusive contract offered to the high-quality downstream firm.

\subsection{Non-exclusive mixed contracts}

In this subsection we consider the case in which the upstream supplier offers a non-contingent contract to one downstream firm and a contingent contract to the other one. In what follows, we focus on the analysis of the case in which the contingent contract is offered to the lowquality downstream firm and the non-contingent contract to the high-quality one. As is shown in the Appendix 2, the reverse case is always dominated by the upstream supplier offering contingent contracts to both downstream firms.

\footnotetext{
${ }^{14}$ see footnote 13.
} 
When $\mathcal{D}_{l}$ is offered a contingent contract, $\mathcal{D}_{h}$ knows that in case of a breakdown in its negotiations with the upstream supplier, $\mathcal{U}$ and $\mathcal{D}_{l}$ will behave as a chain of monopolies. Therefore, the outside option for the upstream supplier in the negotiations with the high quality downstream firm is $\frac{\mu u_{l}}{4}$. Conversely, the outside option for $\mathcal{U}$ in the negotiations with $\mathcal{D}_{l}$ stems from the fact that its contract with $\mathcal{D}_{h}$ cannot include clauses that are contingent on the disagreement between $\mathcal{U}$ and $\mathcal{D}_{l}$ itself. Letting $T_{i}^{M} \equiv\left(w_{i}^{M}, t_{i}^{M}\right)$ be the equilibrium contract signed between $\mathcal{U}$ and $\mathcal{D}_{i}, i=h, l$, the generalized Nash products are

$$
\begin{aligned}
N P_{h}^{M}\left(T_{h}, T_{l}^{M}\right) & =\left[\hat{\Pi}\left(T_{h}, T_{l}^{M}\right)-\frac{u_{l}}{4} \mu\right]^{\mu} \hat{\pi}_{h}\left(T_{h}, w_{l}^{M}\right)^{1-\mu}, \\
N P_{l}^{M}\left(T_{h}^{M}, T_{l}\right) & =\left[\hat{\Pi}\left(T_{h}^{M}, T_{l}\right)-\hat{\Pi}_{m}\left(T_{h}^{M}\right)\right]^{\mu} \hat{\pi}_{l}\left(T_{l}, w_{h}^{M}\right)^{1-\mu} .
\end{aligned}
$$

As in the case of contingent contracts, the generalized Nash products (24) and (25) are not always concave at the solution of the system of the first-order conditions. In particular, the concavity of $N P_{h}^{M}(\cdot)$ is guaranteed either when $\frac{u_{l}}{u_{h}} \leq \frac{4}{5}$ or when $\frac{u_{l}}{u_{h}}>\frac{4}{5}$ and $\mu \leq$ $\frac{8 u_{h}^{2}-4 u_{h} u_{l}-u_{l}^{2}}{u_{l}\left(6 u_{h}-u_{l}\right)}<1 .^{15}$

In this parameter constellation, standard maximization techniques ${ }^{16}$ lead to the equilibrium contracts

$$
\begin{aligned}
& T_{h}^{M}=\left(w_{h}^{M}, t_{h}^{M}\right)=\left(\frac{u_{l}}{4}, \frac{8 \mu u_{h}^{2}-2\left(3 \mu^{2}-\mu+2\right) u_{h} u_{l}+(1-\mu)^{2} u_{l}^{2}}{32 u_{h}}\right), \\
& T_{l}^{M}=\left(w_{l}^{M}, t_{l}^{M}\right)=\left(\frac{u_{l}^{2}}{4 u_{h}}, \frac{u_{l}\left[2 \mu u_{h}-(3-\mu) u_{l}\right]}{32 u_{h}}\right) .
\end{aligned}
$$

Note that the fixed fee offered to the low-quality downstream firm $t_{l}^{M}$ is equal to the respective one under non-contingent contracts $t_{l}^{N}$. This is because $t_{l}^{M}$ does not depend on the fixed fee offered to the high-quality firm. Yet, the latter differs from the fixed fee offered to the high-quality firm under non-contingent contracts.

The following Lemma summarizes our findings.

Lemma 4. If the upstream supplier offers a contingent contract to the low-quality downstream firm and a non-contingent contract to the high-quality one then:

(i) If $\frac{u_{l}}{u_{h}} \leq \frac{4}{5}$, or $\frac{u_{l}}{u_{h}}>\frac{4}{5}$ and $\mu \leq \frac{8 u_{h}^{2}-4 u_{h} u_{l}-u_{l}^{2}}{u_{l}\left(6 u_{h}-u_{l}\right)}<1$, the equilibrium contract terms are given by (26) and (27). The equilibrium prices are $p_{h}^{M}=\frac{2 u_{h}-u_{l}}{4}, p_{l}^{M}=\frac{u_{l}}{4}$, and the

\footnotetext{
${ }^{15}$ When these conditions fail to hold, then in the interior solution the high-quality downstream firm makes negative profits and thus, its participation constraint is violated. To keep the high-quality downstream firm in the market, the upstream should adjust the fixed fee downwards. However, as it is shown in Appendix 3, the latter strategy is dominated by the upstream supplier offering an exclusive contract to the high-quality downstream firm.

${ }^{16}$ see footnote 13 .
} 
equilibrium demands are $D_{h}^{M}=\frac{1}{2}, D_{l}^{M}=\frac{1}{4}$. The equilibrium profits of the upstream supplier are $\Pi^{M}=\frac{\mu\left(8 u_{h}^{2}+(4-6 \mu) u_{h} u_{l}+(\mu-1) u_{l}^{2}\right)}{32 u_{h}}$, and those of the downstream firms are $\pi_{h}^{M}=\frac{(1-\mu)\left[8 u_{h}^{2}-\mu u_{l}\left(6 u_{h}-u_{l}\right)-\left(4 u_{h}+u_{l}\right) u_{l}\right]}{32 u_{h}}$ and $\pi_{l}^{M}=\frac{(1-\mu) u_{l}\left(2 u_{h}+u_{l}\right)}{32 u_{h}}$. The consumer surplus is $C S^{C}=\frac{u_{h}}{8}+\frac{5}{32} u_{l}$.

(ii) If $\frac{u_{l}}{u_{h}}>\frac{4}{5}$ and $\frac{8 u_{h}^{2}-4 u_{h} u_{l}-u_{l}^{2}}{u_{l}\left(6 u_{h}-u_{l}\right)}<\mu<1$, the upstream supplier must adjust the fixed fee downwards in order to incentivize the high-quality firm to sign the contract. These nonexclusive mixed contracts are, however, dominated by an exclusive contract offered to the high-quality downstream firm.

Proof. See Appendix 3 for the part ii).

\section{Contract selection}

We are now in a position to determine the optimal contract choice for the upstream supplier. Let $r \equiv \frac{u_{l}}{u_{h}}$, with $r \in(0,1)$. The following Proposition states our main result.

Proposition 1. Let $\mu_{1}(r) \equiv \frac{r(1-r)}{6-r}$ and $\mu_{2}(r) \equiv \frac{2(1-r)}{6-r}$, with $0<\mu_{1}(r)<\mu_{2}(r)<\frac{3}{4}$. The upstream supplier offers:

(i) two non-exclusive, non-contingent contracts for $\mu \in\left[0, \mu_{1}(r)\right]$,

(ii) a non-exclusive, non-contingent contract to downstream firm $\mathcal{D}_{h}$ and a non-exclusive, contingent contract to downstream firm $\mathcal{D}_{l}$ for $\mu \in\left[\mu_{1}(r), \mu_{2}(r)\right]$,

(iii) two non-exclusive, contingent contracts for $\mu \in\left[\mu_{2}(r), \frac{3}{4}\right]$,

(iv) an exclusive contract to downstream firm $\mathcal{D}_{h}$ for $\mu \in\left[\frac{3}{4}, 1\right]$.

Proof. See Appendix 4.

Figure 1 depicts in the $(r, \mu)$-space the equilibrium contract selection. Two main mechanisms govern the choice of the upstream supplier over the type of contract(s) to be offered to the downstream firms. The first mechanism concerns the choice between an exclusive contract and two non-exclusive contracts. The second one applies to the choice within the class of non-exclusive contracts and refers to the specific type of contract to be offered to each of the downstream firms.

As far as the first trade-off is concerned, the forces at stake are as follows. On the one hand, an exclusive contract allows $\mathcal{U}$ to create a monopoly in the downstream market. As a consequence, aggregate industry profits are maximized and are equal to those of a 


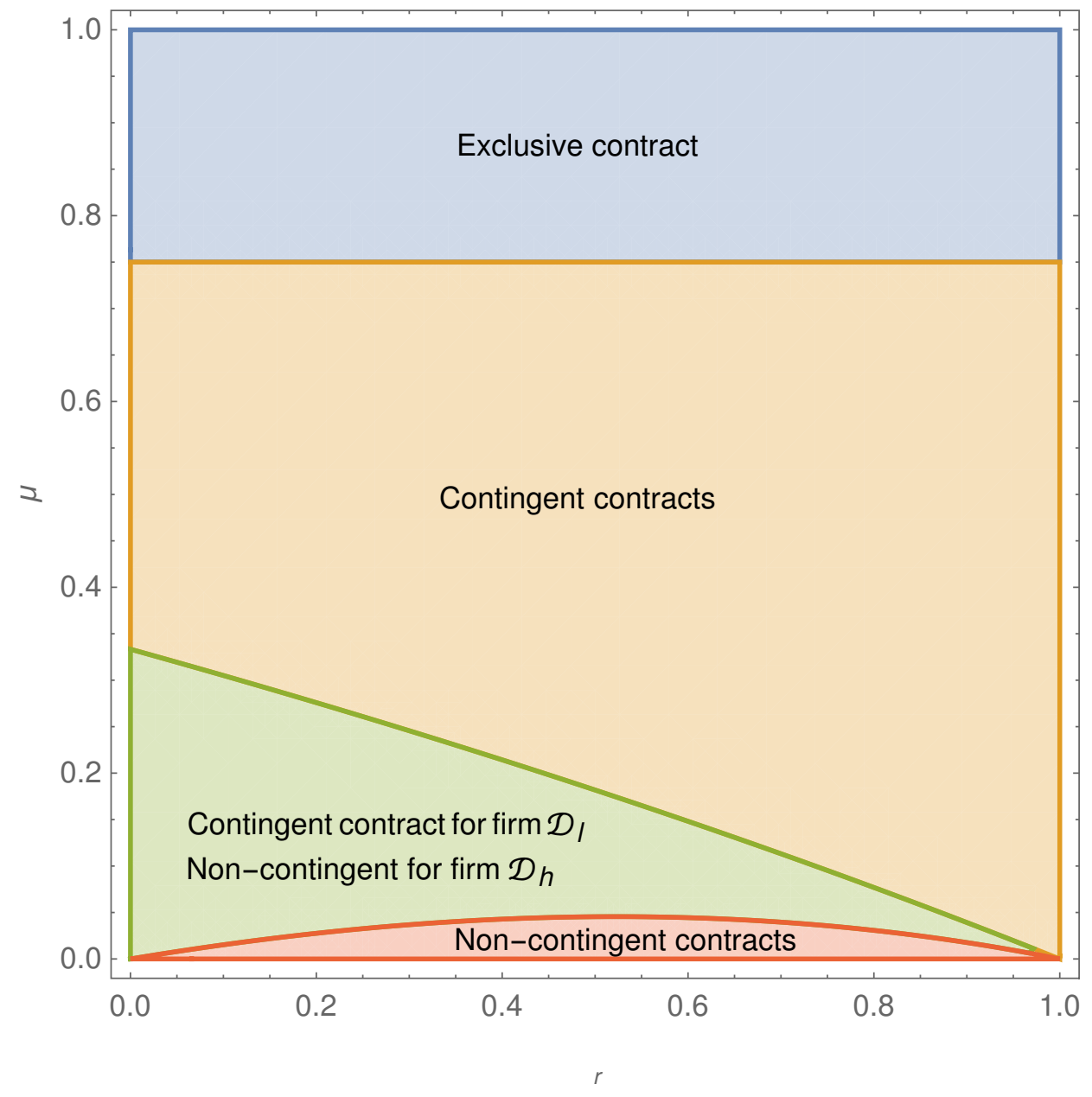

Figure 1: Equilibrium contract partition under price competition. 
vertically integrated monopolist (Remember that the equilibrium contract is such that the input price is zero, avoiding thus double-marginalization). These profits are then apportioned between $\mathcal{U}$ and $\mathcal{D}_{h}$ according to their respective bargaining powers. Yet, because of contract exclusivity, the upstream supplier has no outside option in the bargaining with $\mathcal{D}_{h}$, which tends to reduce its equilibrium profits. On the other hand, by selecting non-exclusive contracts, $\mathcal{U}$ enjoys an outside option in its negotiations with each of the downstream firms, which improves its bargaining position for all values of $\mu$. Yet, this comes at the cost of generating a profit-dissipating competition in the downstream market (which is only partially ameliorated by above marginal cost input pricing). The latter coupled with the well-known upstream monopolist's commitment problem, generated by the simultaneous and separate negotiations with the two downstream firms, tends to reduce its equilibrium profits. As a consequence, the upstream supplier prefers to avoid creating competition in the downstream market as long as it has high bargaining power $\left(\mu>\frac{3}{4}\right)$ and can, therefore, appropriate most of the maximized aggregate industry profits. By contrast, when its bargaining power is lower $\left(\mu \leq \frac{3}{4}\right), \mathcal{U}$ prefers entering into non-exclusive relations that generate favorable outside options at the negotiation stage. By doing so, it strengthens its bargaining position and compensates for the lower bargaining power. At the expense, however, of a reduction in the aggregate industry profits, part of which it could appropriate.

Regarding the choice of the specific type of contract(s) within the set of non-exclusive contracts, the following observations are in order. First, when $\mathcal{U}$ selects a contract type (contingent vs. non-contingent) to offer to $\mathcal{D}_{i}$, it actually determines its outside option in the negotiation with $\mathcal{D}_{j}$. With this in mind, observe that under a contingent contract with $\mathcal{D}_{i}$, the outside option of $\mathcal{U}$ in its negotiations with $\mathcal{D}_{j}$ is its share of the vertically integrated monopoly profit (remember that the input price is zero in this case). Under non-contingent contracts, by contrast, the input prices are above zero, due to the commitment problem. As input prices do not depend on the upstream bargaining power, they remain positive even when $\mu$ is close to zero. Therefore, as $\mu$ becomes very small, the outside option of the upstream supplier goes to zero under contingent contracts, whereas it remains positive under noncontingent contracts (due to the input price still being positive). This entails that the outside options of the upstream supplier become larger under non-contingent than under contingent contracts for $\mu$ small enough. In particular, in the bargaining with downstream firm $\mathcal{D}_{h}$, this occurs when $\mu<\mu_{1}(r)$, and in the bargaining with $\mathcal{D}_{l}$, when $\mu<\mu_{2}(r)$. Therefore, the upstream supplier's bargaining position is affected by the type of contract(s) it selects. Hence, starting from a high value of the bargaining power $\left(\mu \in\left[\mu_{2}(r), \frac{3}{4}\right]\right)$, the most favorable outside options for the upstream supplier are guaranteed by two contingent contracts. As $\mu$ decreases $\left(\mu \in\left[\mu_{1}(r), \mu_{2}(r)\right]\right)$, the outside option in the negotiation with $\mathcal{D}_{l}$ becomes larger with a non-contingent than with a contingent contract signed with $\mathcal{D}_{h}$. Lastly, when $\mu$ is 
small $\left(\mu \in\left[0, \mu_{1}(r)\right]\right)$, also the outside option in the negotiation with $\mathcal{D}_{h}$ becomes larger under a non-contingent contract. The latter sheds light on why the upstream supplier never finds it optimal to offer a contingent contract to $\mathcal{D}_{h}$ and a non-contingent contract to $\mathcal{D}_{l}$.

\section{Discussion of equilibrium outcomes}

We should stress again that equilibrium input prices do not depend on the contingency or not of the non-exclusive contracts. This is not surprising, because the variable part of the twotariff contract $w_{i}$ maximizes the excess joint profits of the $\left(\mathcal{U}, \mathcal{D}_{i}\right)$ negotiating pair, whereas the fixed part $t_{i}$ apportions the maximized excess joint profits to each of the involved parties according to their respective bargaining powers. As a result, input prices are independent of the distribution of the bargaining power. Note however that equilibrium input prices are higher than the upstream marginal cost because of the upstream monopolist's endeavor to relax downstream price competition. Yet, the upstream monopolist is unable to publicly commit to contracts and due to this commitment problem (O'Brien and Shaffer, 1992), the equilibrium contract terms fail to maximize the aggregate industry profits.

As equilibrium input prices coincide under all types of non-exclusive contracts, the final goods prices are the same as well. This, in turn, entails that equilibrium demands and consumer surplus are the same too (compare Lemmata 2,3 and 4). By contrast, the profits accruing to the upstream supplier and the downstream firms differ, because the equilibrium fixed fees are different under contingent, non-contingent and mixed contracts, reflecting the differences in the upstream monopolist's outside options.

Interestingly, the fixed fees may be positive or negative depending on the distribution of the bargaining power, as reported in the following Lemma. Letting $R_{l}^{i} \equiv w_{l}^{i} D_{l}^{i}+t_{l}^{i}, i \in\{C, M, N\}$ be the upstream supplier's profits from selling input to the low-quality firm, we obtain the following results.

Lemma 5. (i) If the optimal contracts are non-contingent (i.e., $\mu \in\left[0, \mu_{1}(r)\right]$ ), then the fixed fees, $t_{h}^{N}$ and $t_{l}^{N}$, are both negative; moreover, $R_{l}^{N}<0$.

(ii) If the optimal contracts are mixed (i.e., $\left.\mu \in\left[\mu_{1}(r), \mu_{2}(r)\right]\right)$, then:

$$
\begin{aligned}
& \forall r>0.448 \Rightarrow t_{h}^{M}<0, \text { otherwise } t_{h}^{M} \gtreqless 0 \Leftrightarrow \mu \gtreqless \frac{4+r-r^{2}-\sqrt{16+8 r-31 r^{2}+8 r^{3}}}{\left(6 r-r^{2}\right)} \equiv \mu_{h}^{M}(r) \\
& \forall r>0.202 \Rightarrow t_{l}^{M}<0, \text { otherwise } t_{l}^{M} \gtreqless 0 \Leftrightarrow \mu \gtreqless \frac{3 r}{2+r} \equiv \mu_{l}^{M}(r) \\
& \forall r>0.472 \Rightarrow R_{l}^{M}<0, \text { otherwise } \quad R_{l}^{M} \gtreqless 0 \Leftrightarrow \mu \gtreqless \frac{r}{2+r} \equiv \mu_{R}^{M}(r)
\end{aligned}
$$


(iii) If the optimal contracts are contingent (i.e., $\left.\mu \in\left[\mu_{2}(r), 3 / 4\right]\right)$, then:

$$
\begin{aligned}
& t_{h}^{C} \gtreqless 0 \Leftrightarrow \mu \gtreqless \frac{8-r-\sqrt{64-64 r+r^{2}}}{8} \equiv \mu_{h}^{C}(r) \\
& t_{l}^{C} \gtreqless 0 \Leftrightarrow \mu \gtreqless \frac{6+r-\sqrt{20-20 r+r^{2}}}{8} \equiv \mu_{l}^{C}(r) \\
& R_{l}^{C} \gtreqless 0 \Leftrightarrow \mu \gtreqless \frac{3-\sqrt{5}}{4} \equiv \mu_{R}^{C}(r)
\end{aligned}
$$

Figure 2 depicts the various regions described in Lemma 5. In the purple-shaded areas the respective variables take positive values, whereas in the yellow-shaded areas they take negative values.

Under all types of non-exclusive contracts, if the bargaining power of the upstream supplier is large ( $\mu$ high), the share of the excess joint profits of each negotiating pair accruing, via the fixed fee, to the upstream supplier is large. As $\mu$ decreases, the fixed fees shrink. Ultimately, when $\mu$ becomes sufficiently small, the fixed fees become negative: The upstream monopolist partially subsidizes, through the fixed fees, the downstream firms, yet it receives positive payments via sales at input prices above its marginal cost. Surprisingly, the nonexclusive contract offered to the low-quality downstream firm can, in fact, generate losses for the upstream supplier, i.e., the positive revenues from input sales can be lower than the negative fixed fee (see yellow region in Figure 2c). ${ }^{17}$ In this case, the upstream supplier optimally suffers such a loss in order to gain a stronger outside option in the negotiations with the high-quality downstream firm that sells the "high value-added" product. The above are particularly relevant under non-contingent contracts in which case both fixed fees $t_{h}^{N}$ and $t_{l}^{N}$ are always negative and at the same time, the revenue collected by input sales to $\mathcal{D}_{l}$ does not cover the negative fixed fee - transfer downstream (i.e., $R_{l}^{N}<0$ ).

The following Proposition summarizes our findings.

Proposition 2. Under non-contingent, non-exclusive equilibrium contracts, the fixed fees always act as subsidies to the downstream firms, and moreover, the contract offered to the lowquality downstream firm generates a loss for the upstream supplier. These observations hold also under contingent and mixed, non-exclusive equilibrium contracts as long as the bargaining power of the upstream supplier is sufficiently low.

Note that the parameter space in which fixed fees are negative grows larger as the products become less differentiated (as $r$ increases). Intuitively, the less differentiated the products, the smaller the industry producer surplus to be shared among the upstream supplier and the downstream firms. As downstream firms pay positive input prices, but should still earn

\footnotetext{
${ }^{17}$ Note that for any $\mu$ we have $R_{h}^{i}=w_{h}^{i} D_{h}^{i}+t_{h}^{i}>0$, i.e., the contract offered to the high-quality firm generates always gains for the upstream supplier.
} 


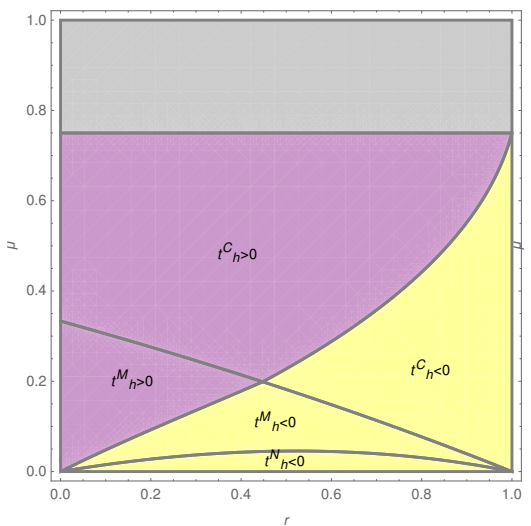

(a) $t_{h}^{C}, t_{h}^{M}$

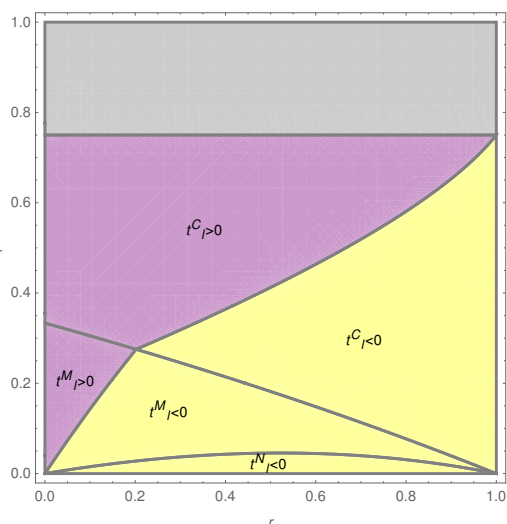

(b) $t_{l}^{C}, t_{l}^{M}$

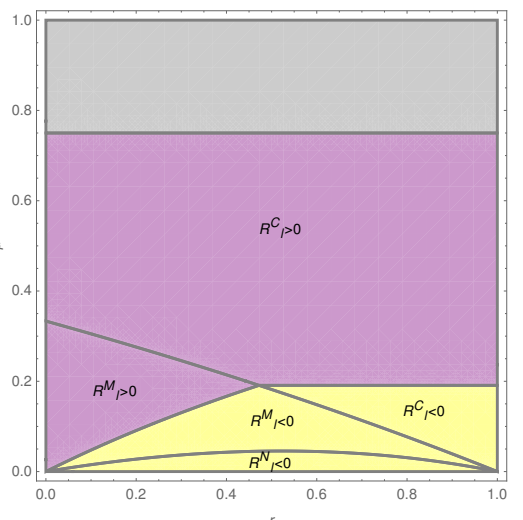

(c) $R_{l}^{C}, R_{l}^{M}$

Figure 2: Optimal tariffs and total profit from $\mathcal{D}_{l}$ under Contingent and Mixed equilibrium contracts.

overall non-negative profits, a higher part of the industry producer surplus accrues to them as the goods become less differentiated.

\section{Extensions}

\subsection{Quantity competition}

In this Section, we explore the optimal choice of contracts by the upstream supplier under the alternative assumption of downstream quantity competition. It is well-known that competition in quantities softens the competitive pressure on firms in one-tier industries (see e.g. Singh and Vives, 1984), but this result is not robust when considering multi-layer industries (Alipranti et al., 2014). As most of the analysis parallels that of downstream price competition, we report hereafter only our main findings. ${ }^{18}$ Figure 3 depicts the equilibrium contract configurations in the $(r, \mu)$ space of parameters.

The main message drawn from Figure 3 is that, under downstream quantity competition, the equilibrium contract selection conveys important similarities to the case of price competition considered above. In particular, when $\mathcal{U}$ has relatively high bargaining power, it selects to enter into an exclusive relationship with $\mathcal{D}_{h}$. For intermediate values of the bargaining power, $\mathcal{U}$ offers two non-exclusive, contingent contracts. Whereas for lower values of $\mu, \mathcal{U}$ offers a contingent contract to $\mathcal{D}_{l}$ and a non-contingent one to $\mathcal{D}_{h}$. These contract offers are qualitatively similar to the case of downstream price competition. Yet, in contrast to price competition, $\mathcal{U}$ never offers non-contingent contracts to both downstream firms.

\footnotetext{
${ }^{18}$ Needless to say, the detailed analysis, which follows exactly the same steps as under downstream price competition, is available upon request.
} 


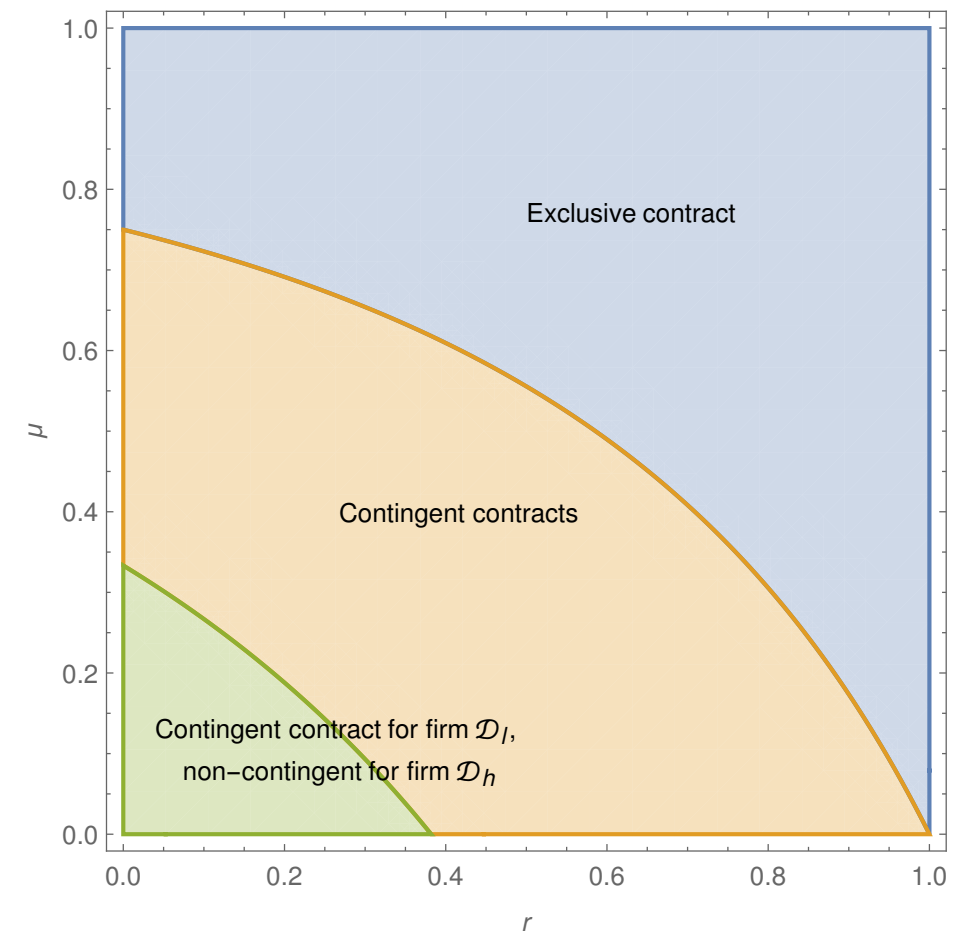

Figure 3: Equilibrium contract partition under quantity competition.

A few observations are worth making here, that will help in pinpointing the similarities and divergences relative to the downstream price competition case. First, under exclusive contracts there is no competition downstream and the equilibrium outcome is as in Section 3.1. Second, equilibrium input prices again coincide under different non-exclusive contract configurations, yet they are now below upstream marginal cost due to the commitment problem (see, e.g. Alipranti et al., 2014). The latter tends to reduce, relative to the downstream price competition case, the profits accruing to the upstream supplier.

An immediate consequence is that non-contingent contracts offered to both downstream firms are never optimal for the upstream supplier. In fact, when $\mu$ is low, the fixed fees $t_{i}, i=h, l$ are small. In addition, the upstream supplier's outside options under non-contingent contracts are negative. As a consequence, $\mathcal{U}$ 's profits are small and eventually become negative for low enough $\mu$ (and are thus significantly lower than in the case of downstream price competition). By contrast, a contingent contract offered to $\mathcal{D}_{l}$, along with a non-contingent one offered to $\mathcal{D}_{h}$, makes the outside option of $\mathcal{U}$ in its bargaining with $\mathcal{D}_{l}$ positive and as a consequence, the mixed contract configuration dominates non-contingent contacts offered to both downstream firms.

The intuition regarding the upstream supplier's choice between an exclusive contract of- 
fered to $D_{h}$ and non-exclusive, contingent contracts offered to both downstream firms is qualitatively similar to that under downstream price competition. This is also the case for the upstream supplier's choice between the latter contracts and the mixed contracts.

The comparison of the regions in which mixed contracts are selected - the green areas in Figures 1 and 3 - leads to a last remark. Contrary to the case of downstream price competition, mixed contracts under quantity competition are never optimal when the degree of vertical product differentiation is low (large $r$ ). ${ }^{19}$ In the latter case downstream competition is fierce and as a consequence, the total producer surplus generated in the industry is small, entailing that $\mathcal{U}$ 's outside options are small too. This implies that under mixed contracts, as the products become more homogeneous, the outside option of $\mathcal{U}$ in the negotiation with $D_{l}$ becomes small (and eventually negative) even for relatively large values of $\mu$. By contrast, under contingent contracts, the upstream supplier's outside options, albeit lower under downstream quantity competition, are non-negative even when the degree of product differentiation is small. As a consequence, $\mathcal{U}$ opts to offer contingent contracts to both downstream firms in this case.

\subsection{Alternative utility specification}

One natural question that may arise is to which extent our results rely on the assumption of vertically differentiated products with Mussa and Rosen (1978) utility function (MU, henceforth). In this section, we demonstrate that qualitatively similar results hold when the products are horizontally differentiated and the utility function is as specified in Bowley (1924), Spence (1976) and Dixit (1979) (BSD, henceforth). In particular, the utility of the representative consumer is

$$
U\left(D_{1}, D_{2}\right)=\alpha D_{1}+\alpha D_{2}-\frac{1}{2}\left(D_{1}^{2}+D_{2}^{2}+2 \gamma D_{1} D_{2}\right)+m
$$

where $D_{i}$ is the quantity of good $i, i \in\{1,2\}$ that the consumer purchases and $m$ is the respective quantity of the "composite" good. The consumer's optimal behavior gives rise to the following linear demand system

$$
D_{1}\left(p_{1}, p_{2}\right)=\frac{\alpha(1-\gamma)-p_{1}+\gamma p_{2}}{1-\gamma^{2}}, \quad D_{2}\left(p_{1}, p_{2}\right)=\frac{\alpha(1-\gamma)-p_{2}+\gamma p_{1}}{1-\gamma^{2}},
$$

where $p_{1}$ and $p_{2}$ are the prices of goods 1 and 2 respectively, $\alpha>0$ and $\gamma \in(0,1)$ indicates the degree of product substitutability. When $\gamma$ is close to zero, the goods are almost independent, whereas when $\gamma$ tends to one, the goods become almost homogenous. The most remarkable

\footnotetext{
${ }^{19}$ Indeed, in order mixed contracts to be optimal, a necessary (but not sufficient) condition is that $r<0.382$, see figure 3 .
} 


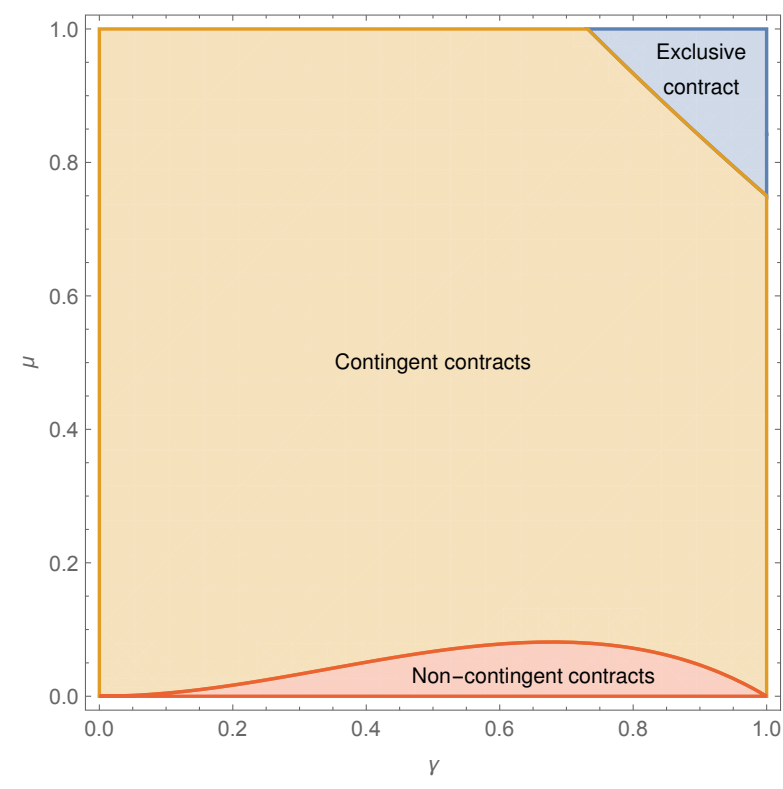

(a) Price competition

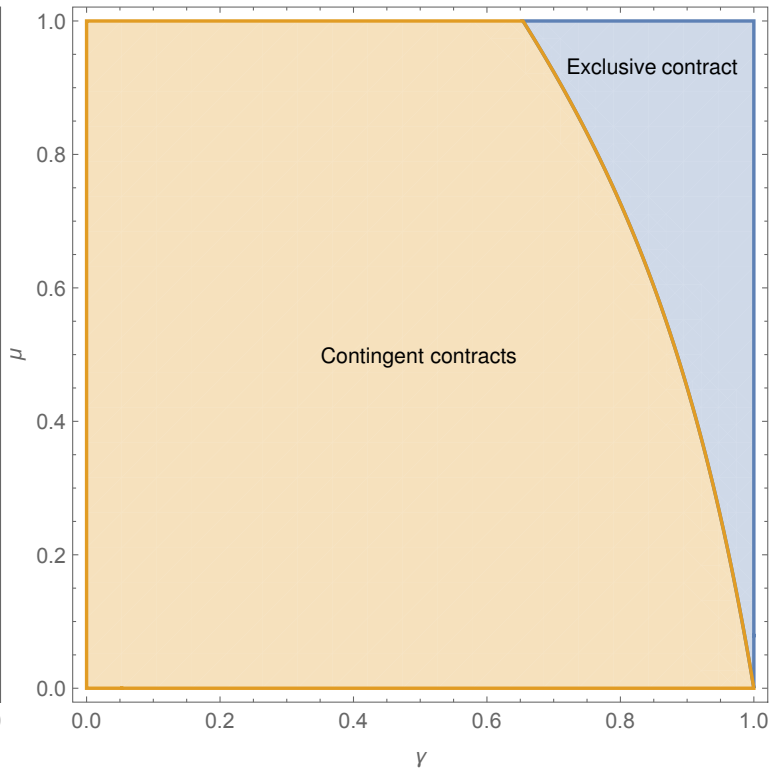

(b) Quantity competition

Figure 4: Equilibrium contract configurations with BSD utility.

differences between the present model and our main model are that under the utility function in (28) (i) the goods are symmetric from the point of view of the consumer and (ii) the consumer is not restricted to purchase discrete quantities of the goods.

The analysis here closely follows the steps presented in the previous sections. To save on space, we will present the main findings under the BSD utility specification diagrammatically. ${ }^{20}$ Figure 4, panel (4a) and panel (4b), depict the equilibrium contract configurations under downstream price and quantity competition, respectively.

As can easily be seen from Figure 4, our findings under the BSD utility specification convey important similarities with those under the MR utility specification. The most remarkable difference is that the upstream supplier never finds it optimal to offer mixed contracts. In contrast to the MR utility specification, as the consumer's preferences are symmetric over the two goods in this case, the upstream supplier is indifferent between offering the contingent contract to downstream firm $1\left(\mathcal{D}_{1}\right)$ and the non-contingent to downstream firm $2\left(\mathcal{D}_{2}\right)$ or vice versa. Mixed contracts are then dominated either by contingent or by non-contingent contracts offered to both downstream firms. In particular, under quantity competition, mixed contracts are always dominated by two contingent contracts, whereas under price competition they are dominated by two contingent (non-contingent) contracts as long as $\mu$ is high (low). ${ }^{21}$

\footnotetext{
${ }^{20}$ The detailed analysis is available upon request.

${ }^{21}$ The critical value is $\bar{\mu}(\gamma) \equiv \frac{2 \gamma^{2}\left(2-\gamma-\gamma^{2}\right)}{8+\gamma(1+\gamma)\left(2-\gamma^{2}\right)}$ which separates the regions of contingent and non-contingent contracts in Figure 4 panel (4a).
} 
Clearly, under quantity competition, a non-contingent contract signed with $\mathcal{D}_{i}$ leads to an outside option for the upstream supplier in its bargaining with $\mathcal{D}_{j}$ smaller than when it signs a contingent contract with $\mathcal{D}_{i}$. As a result, two contingent contracts always dominate a mixed contract. Under price competition, for low $\mu, \mathcal{U}$ 's outside option in the bargaining with $\mathcal{D}_{j}$ under a contingent contract signed with $\mathcal{D}_{i}$ is smaller than when it signs a non-contingent contract with $\mathcal{D}_{i}$. As a result, two non-contingent contracts dominate mixed contracts for low values of $\mu$. The reverse reasoning holds for high $\mu$ and thus, two contingent contracts dominate mixed contracts.

Another difference lies in the characteristics of the parameter region in which an exclusive contract is chosen by the upstream supplier. In fact, in the MR utility specification case, under both price and quantity downstream competition, an exclusive contract is offered to $\mathcal{D}_{h}$ for any degree of vertical product differentiation (provided that $\mu$ is large enough). This is not so with the BSD utility specification, in which case an exclusive contract is offered only if goods are close enough substitutes ( $\gamma$ high enough). This can be seen by comparing Figures (1) and (3), with (4). This is due to the different nature of the two models. Under the MR utility specification, the goods are vertically differentiated, with all consumers a priori preferring the high-quality over the low-quality good. The coexistence of high- and lowquality variants has a profit erosion effect that is particularly detrimental on the upstream supplier's revenues from the sales of the high-quality good, i.e., the good that allows for a higher extraction of consumer surplus. As a consequence, when the upstream supplier can extract most of the surplus from the downstream market ( $\mu$ is high), it prefers to avoid profit-dissipating downstream competition and opts thus for an exclusive contract with the high-quality downstream firm. Under the BSD utility specification, goods are symmetrically horizontally differentiated, with the representative consumer having a priori no preference for one or the other good. As a consequence, when the degree of product substitutability is low $(\gamma$ is low), the loss in industry producer surplus due to downstream competition is small. This entails that the upstream supplier prefers to strengthen its bargaining position by offering non-exclusive, contingent contracts to both downstream firms even if it can extract most of the industry producer surplus ( $\mu$ high). By contrast, an exclusive contract becomes rentable only if the degree of product substitutability is high. When $\gamma$ is high, downstream competition has a strong negative effect on industry producer surplus. Then the upstream supplier prefers to avoid profit-eroding downstream competition, opting thus for an exclusive contract. 


\section{Conclusion}

We have investigated the optimal contract choice of an upstream monopolist that may sell an essential input to two downstream firms that produce vertically differentiated products and compete in prices or in quantities in the final goods market. In the outset of the game, the upstream supplier can offer an exclusive contract to one of the downstream firms, or nonexclusive contracts to both of them, in which case each of the contracts could be contingent or non-contingent. Contract terms negotiations, and in particular over two-part tariffs, are then conducted between the upstream supplier and the downstream firm(s). A non-contingent contract does not allow renegotiation of contract terms with a downstream firm in case that the upstream supplier does not reach an agreement with the rival downstream firm. A contingent contract instead allows for different contract terms in case of agreement and in case of disagreement in the negotiations between the upstream supplier and the rival downstream firm.

We show that the distribution of the bargaining power and the degree of vertical product differentiation play a crucial role in determining the equilibrium outcome. In particular, when the bargaining power of the upstream supplier is relatively high, it prefers to sign an exclusive contract with the high-quality downstream firm. In this way, it avoids downstream competition that erodes aggregate industry profits and moreover, it extracts most of the producer surplus generated by the ensuing vertically integrated market structure. For lower values of bargaining power, the upstream supplier opts for non-exclusive contracts. In this way, the upstream supplier generates outside options in its negotiations with the downstream firms, at the cost however of increasing downstream competition. By strengthening its bargaining position, it obtains a larger share of an otherwise smaller industry producer surplus and increases thus its profits. Further, we show that for intermediate bargaining power values, the upstream supplier prefers to offer contingent contracts to both downstream firms; whereas for lower values, it opts for mixed contracts, i.e., a contingent contract to the low-quality downstream firm and a non-contingent to the high-quality one. Finally, the upstream supplier offers non-contingent contracts to both downstream firms only if the upstream bargaining power is quite low and downstream firms compete in prices. This never occurs under downstream quantity competition because the upstream monopolist suffers from a strong commitment problem that results to negative input prices.

Finally, we have shown that our main findings are qualitatively similar when we consider symmetrically horizontally differentiated markets. In those markets, if we replace the degree of vertical product differentiation with the degree of product substitutability, we obtain a similar partition of the parameter space regarding the upstream supplier's contract choices.

Our analysis leads to a number of testable implications. In markets with a powerful 
upstream supplier, we should observe foreclosure in the downstream market. In particular, low-quality downstream firms are expected to be foreclosed by the upstream monopolist. By contrast, when the upstream supplier is not so powerful, we should observe non-exclusive contracts offered to downstream firms. In addition, the "complexity" of non-exclusive contracts is expected to be positively related to the bargaining power of the upstream supplier: More powerful suppliers should sign contracts including clauses that allow for renegotiation in case of an increase in downstream concentration, whereas in contracts signed by less powerful upstream suppliers, such clauses are expected to be absent. Furthermore, mixed contracts should mainly be observed in markets where goods dispose some vertical product differentiation characteristics, whereas they should be much less common in markets for horizontally differentiated goods. Finally, in markets with quantity competition, exclusive contracts should be observed more frequently than in markets characterized by price competition.

Our analysis suggests several lines for future research. First, one direction is to consider that the two downstream firms have different bargaining powers relative to the upstream supplier. We expect that our intuitive arguments concerning the choice between exclusive and non-exclusive contracts would apply in this case too. However, due to the asymmetry in bargaining powers, mixed contracts with a contingent contract offered to high-quality firm and a non-contingent to the low-quality firm could emerge. Another direction is to let the number of competing downstream firms increase. The configuration of contracts to be offered by the upstream supplier is expected to be richer now, but the upstream bargaining power will still play a significant role in its choice of specific contracts. One should expect that the higher the upstream bargaining power, the more concentrated the downstream market will be.

\section{References}

Acharyya, R. (1998). "Monopoly and product quality: Separating or pooling menu?" Economics Letters, 61(2):187-194.

Alipranti, M., Milliou, C., and Petrakis, E. (2014). "Price vs. quantity competition in a vertically related market". Economics Letters, 124(1):122-126.

Bacchiega, E., Bonroy, O., and Mabrouk, R. (2013). "Paying not to sell". Economics Letters, 121(1):137-140.

Bazerman, M. H. and Gillespie, J. J. (1998). "Betting on the future: the virtues of contingent contracts." Harvard Business Review, 77(5):155-60.

Bonnet, C. and Dubois, P. (2010). "Inference on vertical contracts between manufacturers and 
retailers allowing for nonlinear pricing and resale price maintenance". The RAND Journal of Economics, 41(1):139-164.

Bowley, A. L. (1924). The mathematical groundwork of economics. Oxford University Press, reprinted by A.M. Kelley New York, 1965.

Byialogorsky, E. and Gerstner, E. (2004). "Contingent Pricing to Reduce Price Risks". Marketing Science, 23(1):146-155.

Chambolle, C. and Villas-Boas, S. B. (2015). "Buyer power through the differentiation of suppliers". International Journal of Industrial Organization, 43:56-65.

de Fontenay, C. C. and Gans, J. S. (2005). "Vertical Integration in the Presence of Upstream Competition". RAND Journal of Economics, pages 544-572.

Dixit, A. K. (1979). "A model of duopoly suggesting a theory of entry barriers". The Bell Journal of Economics, 10(1):20-32.

European Commission (1999). "Buyer Power and its Impact on Competition in the Food Retail Distribution Sector of the European Union". Technical report, European Commission, DG IV, Brussels.

FTC (2001). "Report on the Federal Trade Commission Workshop on Slotting Allowances and Other Marketing Practices in the Grocery Industry". Technical report, Federal Trade Commission, Washington D.C.

Gabszewicz, J. J. and Thisse, J.-F. (1979). "Price competition, quality and income disparities". Journal of Economic Theory, 20(3):340-359.

Hart, O. and Holmström, B. (1987). "The Theory of Contracts". In T. Bewley, editor, "Advances in Economic Theory, 5th World Congress of the Econometric Society", pages $71-155$.

Hart, O. and Tirole, J. (1990). "Vertical Integration and Market Foreclosure". Brookings Papers on Economic Activity. Microeconomics, pages 205-286.

Horn, H. and Wolinsky, A. (1988). "Bilateral Monopolies and Incentives for Merger". The RAND Journal of Economics, 19(3):pp. 408-419.

Inderst, R. and Mazzarotto, N. (2008). "Buyer Power in Distribution". In W. Collins, editor, "Issues in Competition Law and Policy", (ABA Antitrust Section Handbook), pages 19531978. ABA. 
Inderst, R. and Wey, C. (2003). "Bargaining, Mergers, and Technology Choice in Bilaterally Oligopolistic Industries". RAND Journal of Economics, pages 1-19.

Inderst, R. and Wey, C. (2007). "Buyer power and supplier incentives". European Economic Review, 51(3):647-667.

Iozzi, A. and Valletti, T. (2014). "Vertical bargaining and countervailing power". American Economic Journal: Microeconomics, 6(3):106-135.

Law, J., editor (2016). A Dictionary of Law. Oxford University Press, online $\left(8^{\text {th }}\right)$ edition.

Marx, L. M. and Shaffer, G. (2010). "Slotting Allowances and Scarce Shelf Space". Journal of Economics \& Management Strategy, 19(3):575-603.

McAfee, R. P. and Schwartz, M. (1994). "Opportunism in Multilateral Vertical Contracting: Nondiscrimination, Exclusivity, and Uniformity". The American Economic Review, 84(1):pp. 210-230.

McAfee, R. P. and Schwartz, M. (1995). "The non-existence of pairwise-proof equilibrium". Economics Letters, 49(3):251-259.

Miklós-Thal, J., Rey, P., and Vergé, T. (2011). "Buyer power and intrabrand coordination". Journal of the European Economic Association, 9(4):721-741.

Milliou, C. and Petrakis, E. (2007). "Upstream horizontal mergers, vertical contracts, and bargaining". International Journal of Industrial Organization, 25(5):963-987.

Mussa, M. and Rosen, S. (1978). "Monopoly and Product Quality". Journal of Economic Theory, 18(2):301-317.

O'Brien, D. P. and Shaffer, G. (1992). "Vertical Control with Bilateral Contracts". The RAND Journal of Economics, 23(3):pp. 299-308.

OECD (1999). "Buying Power of Multiproduct Retailers". Technical report, Series Roundtables on Competition Policy DAFFE/CLP(99)21. OECD, Paris.

Rey, P. and Tirole, J. (2007). "Chapter 33 A Primer on Foreclosure". volume 3 of Handbook of Industrial Organization, pages 2145-2220. Elsevier.

Rey, P. and Vergé, T. (2004). "Bilateral Control with Vertical Contracts". The RAND Journal of Economics, 35(4):pp. 728-746.

Shaffer, G. (1991). "Slotting Allowances and Resale Price Maintenance: A Comparison of Facilitating Practices". The RAND Journal of Economics, 22(1):120-135. 
Shaked, A. and Sutton, J. (1983). "Natural oligopolies". Econometrica, 51(5):1469-1483.

Singh, N. and Vives, X. (1984). "Price and Quantity Competition in a Differentiated Duopoly". The RAND Journal of Economics, 15(4):546-554.

Spence, M. (1976). "Product Differentiation and Welfare". American Economic Review, 66(2):407-14.

Thanassoulis, J. and Smith, H. (2009). "Bargaining between retailers and their suppliers". In

A. Ezrachi and U. Bernitz, editors, "Private Labels, Brands and Competition Policy: The Changing Landscape of Retail Competition", Oxford University Press.

Villas-Boas, S. B. (2007). "Vertical relationships between manufacturers and retailers: Inference with limited data". The Review of Economic Studies, 74(2):625-652.

\section{Appendix}

\section{Contingent contracts: the case $\frac{3}{4}<\mu \leq 1$}

Assume that $\frac{3}{4}<\mu \leq 1$. In this parameter region the low-quality downstream firm cannot enjoy non-negative profits in the interior solution, nonetheless, to sign the contract, it must not incur losses as well. As a consequence, the equilibrium contract must be such that the low quality downstream firm reaps zero profits. Nevertheless, the low quality contract must still maximize the excess joint profits of the $\left(\mathcal{U}, \mathcal{D}_{l}\right)$ pair which, by virtue of the foregoing observation, completely accrue to the upstream supplier. In fact, the fixed fee charged by $\mathcal{U}$ to $\mathcal{D}_{l}$ is adjusted downwards such that the downstream firm is indifferent between signing or not the contract. Thus, the equilibrium contracts are obtained by solving the following problem

$$
\max _{w_{h}, t_{h}} N P_{h}^{C}\left(T_{h}, T_{l}^{C}\right), \quad \max _{w_{l}}\left[\hat{\Pi}\left(T_{h}^{C}, T_{l}\right)+\hat{\pi}_{l}\left(T_{l}, w_{h}^{C}\right)\right], \text { and } \hat{\pi}_{l}\left(T_{l}, w_{h}^{C}\right) \stackrel{t_{l}}{=} 0 .
$$

The equilibrium contracts are then

$$
\begin{aligned}
& T_{h}^{C}=\left(w_{h}^{C}, t_{h}^{C}\right)=\left(\frac{u_{l}}{4}, \frac{4 u_{h} \mu+u_{l}(-3+(3-4 \mu) \mu)}{16}\right) \\
& T_{l}^{C}=\left(w_{l}^{C}, t_{l}^{C}\right)=\left(\frac{u_{l}^{2}}{4 u_{h}}, \frac{\left.u_{l}\left(u_{h}-u_{l}\right)\right)}{16 u_{h}}\right) .
\end{aligned}
$$

The equilibrium prices are $p_{h}^{C}=\frac{2 u_{h}-u_{l}}{4}, p_{l}^{C}=\frac{u_{l}}{4}$, and the equilibrium demands are $D_{h}^{C}=$ 
$\frac{1}{2}, D_{l}^{C}=\frac{1}{4}$. The equilibrium profit of the upstream supplier is $\Pi^{C}=\frac{\mu\left[4 u_{h}+u_{l}(3-4 \mu)\right]}{16}<\Pi_{m}^{*}$. Such a contract is then strictly dominated by an exclusive contract.

\section{Contingent high-quality contract and non-contingent low- quality contract}

Let us consider the case in which $\mathcal{U}$ offers a contingent contract to $\mathcal{D}_{h}$ and a non-contingent contract to $\mathcal{D}_{l}$. Let $T_{i}^{Z} \equiv\left(w_{i}^{Z}, t_{i}^{Z}\right), i=h, l$ be the equilibrium contracts. Using similar arguments as in (3.3) to determine the outside options for the upstream supplier, the generalized Nash products turn out to be

$$
\begin{aligned}
N P_{h}^{Z}\left(T_{h}, T_{l}^{Z}\right) & =\left[\hat{\Pi}\left(T_{h}, T_{l}^{Z}\right)-\hat{\Pi}_{m}\left(T_{l}^{Z}\right)\right]^{\mu} \hat{\pi}_{h}\left(T_{h}, w_{l}^{Z}\right)^{1-\mu}, \\
N P_{l}^{Z}\left(T_{h}^{Z}, T_{l}\right) & =\left[\hat{\Pi}\left(T_{h}^{Z}, T_{l}\right)-\frac{u_{h}}{4} \mu\right]^{\mu} \hat{\pi}_{l}\left(T_{l}, w_{h}^{Z}\right)^{1-\mu} .
\end{aligned}
$$

As in (3.3), (33) and (34) are locally concave at the solution of the focs only if $\mu \leq \frac{2 u_{h}^{2}+2 u_{h} u_{l}-u_{l}^{2}}{4 u_{h}^{2}+2 u_{h} u_{l}-u_{l}^{2}}$ (otherwise, $N P_{l}^{Z}(\cdot)$ is no longer locally concave because $\mathcal{D}_{\ell}$ makes negative profits.) If this condition holds, standard maximization techniques lead to the following equilibrium contracts

$$
\begin{aligned}
& T_{h}^{Z}=\left(w_{h}^{Z}, t_{h}^{Z}\right)=\left(\frac{u_{l}}{4}, \frac{8 \mu u_{h}^{3}-4(1+\mu) u_{h}^{2} u_{l}+2(1-\mu) u_{h} u_{l}^{2}-(1-\mu) u_{l}^{3}}{32 u_{h}^{2}}\right) \\
& T_{l}^{Z}=\left(w_{l}^{Z}, t_{l}^{Z}\right)=\left(\frac{u_{l}^{2}}{4 u_{h}}, \frac{u_{l}\left\{2 \mu(3-2 \mu) u_{h}^{2}+2[(2-\mu) \mu-2] u_{h} u_{l}+(1-\mu)^{2} u_{l}^{2}\right\}}{32 u_{h}^{2}}\right) .
\end{aligned}
$$

Note that as the generalized Nash products $N P_{h}^{Z}\left(T_{h}, T_{l}^{Z}\right)$ and $N P_{h}^{N}\left(T_{h}, T_{l}^{N}\right)$ are similar and do not depend on the fixed fee offered to $\mathcal{D}_{l}$, then $T_{h}^{Z}=T_{h}^{N}$. Then the equilibrium final good prices are $p_{h}^{Z}=\frac{2 u_{h}-u_{l}}{4}, p_{l}^{Z}=\frac{u_{l}}{4}$, and the equilibrium demands are $D_{h}^{Z}=\frac{1}{2}, D_{l}^{Z}=\frac{1}{4}$. The equilibrium profits of the upstream supplier is $\Pi^{Z}=\frac{\mu\left[8 u_{h}^{3}+(2-4 \mu) u_{h}^{2} u_{l}-2(\mu-1) u_{h} u_{l}^{2}+(\mu-1) u_{l}^{3}\right]}{32 u_{h}^{2}}$.

If $\mu>\frac{2 u_{h}^{2}+2 u_{h} u_{l}-u_{l}^{2}}{4 u_{h}^{2}+2 u_{h} u_{l}-u_{l}^{2}}$, the upstream supplier should adjust downwards the fixed fee in order to incentivize the low quality firm to sign the contract. Then the optimal contracts are the solution to

$$
\max _{w_{h}, t_{h}} N P_{h}^{Z}\left(T_{h}, T_{l}^{Z}\right), \quad \max _{w_{l}}\left[\hat{\Pi}\left(T_{h}^{Z}, T_{l}\right)+\hat{\pi}_{l}\left(w_{h}^{Z}, T_{l}\right)\right], \text { and } \hat{\pi}_{l}\left(w_{h}^{Z}, T_{l}\right) \stackrel{t_{l}}{=} 0
$$


Standard maximization techniques then lead to the optimal contracts

$$
\begin{aligned}
& T_{h}^{Z}=\left(w_{h}^{Z}, t_{h}^{Z}\right)=\left(\frac{u_{l}}{4}, \frac{8 \mu u_{h}^{3}-4(1+\mu) u_{h}^{2} u_{l}+2(1-\mu) u_{h} u_{l}^{2}-(1-\mu) u_{l}^{3}}{32 u_{h}^{2}}\right), \\
& T_{l}^{Z}=\left(w_{l}^{Z}, t_{l}^{Z}\right)=\left(\frac{u_{l}^{2}}{4 u_{h}}, \frac{u_{l}\left(u_{h}-u_{l}\right)}{16 u_{h}}\right) .
\end{aligned}
$$

The equilibrium final good prices and demands are as above, while the equilibrium profits of the upstream supplier is $\Pi^{Z}=\frac{u_{l}\left(2 u_{h}^{2}+2 u_{h} u_{l}-u_{l}^{2}\right)+\mu\left(2 u_{h}+u_{l}\right)\left(2 u_{h}-u_{l}\right)^{2}}{32 u_{h}^{2}}$.

Note that as $\Pi^{Z}<\Pi^{C}$, a non-contingent contract offered to $\mathcal{D}_{l}$ and a contingent contract to $\mathcal{D}_{h}$ is strictly dominated by the upstream supplier offering contingent contracts to both firms.

\section{Proof of Lemma 4 part ii)}

If $\mathcal{U}$ offers a contingent contract to $\mathcal{D}_{l}$ and a non-contingent contract to $\mathcal{D}_{h}$ and moreover, $\frac{u_{l}}{u_{h}}>\frac{4}{5}$ and $\frac{8 u_{h}^{2}-4 u_{h} u_{l}-u_{l}^{2}}{u_{l}\left(6 u_{h}-u_{l}\right)}<\mu<1$, in the interior solution the high-quality downstream firm makes negative profits. The upstream supplier should adjust the fixed fee downwards in order to incentivize $\mathcal{D}_{h}$ to sign the contract. Equilibrium contracts is then the solution to the following problem

$$
\max _{w_{l}, t_{l}} N P_{l}^{M}\left(T_{h}^{M}, T_{l}\right), \quad \max _{w_{h}}\left[\hat{\Pi}\left(T_{h}, T_{l}^{M}\right)+\hat{\pi}_{h}\left(T_{h}, w_{l}^{M}\right)\right], \text { and } \hat{\pi}_{h}\left(T_{h}, w_{l}^{M}\right) \stackrel{t_{h}}{=} 0 .
$$

Thus, the equilibrium contracts are

$$
\begin{aligned}
& T_{h}^{M}=\left(w_{h}^{M}, t_{h}^{M}\right)=\left(\frac{u_{l}}{4}, \frac{u_{h}-u_{l}}{4}\right) \\
& T_{l}^{M}=\left(w_{l}^{M}, t_{l}^{M}\right)=\left(\frac{u_{l}^{2}}{4 u_{h}}, \frac{u_{l}\left[2 \mu u_{h}-(3-\mu) u_{l}\right]}{32 u_{h}}\right) .
\end{aligned}
$$

The equilibrium prices are $p_{h}^{M}=\frac{2 u_{h}-u_{l}}{4}, p_{l}^{M}=\frac{u_{l}}{4}$, and the equilibrium demands are $D_{h}^{M}=\frac{1}{2}$, $D_{l}^{M}=\frac{1}{4}$. The equilibrium profit of the upstream supplier is $\Pi^{M}=\frac{8 u_{h}^{2}-2(2-\mu) u_{h} u_{l}-(1-\mu) u_{l}^{2}}{32 u_{h}}<$ $\Pi_{m}^{*}$. Hence, this pair of contracts is strictly dominated by an exclusive contract offered to the high-quality firm.

\section{Proof of Proposition 1}

As we have seen above, some contract configurations are strictly dominated strategies for the upstream supplier. This is so for those contracts in which the upstream supplier should adjust 
the fixed fee downwards to motivate the high, or the low, quality downstream firm to sign the contract. These contracts are strictly dominated by an exclusive contract offered to $\mathcal{D}_{h}$ (see Appendix 1 and 3). In addition, a non-contingent contract offered to $\mathcal{D}_{l}$ and a contingent contract to $\mathcal{D}_{h}$ is also strictly dominated strategy by contingent contracts offered to both downstream firms (see Appendix 2).

After the elimination of strictly dominated strategies, we determine the optimal contracts for the upstream supplier in the first stage by simply comparing its profits at the equilibria of each subgame

(i) if $\mu \in\left[0, \mu_{1}(r)\right)$, then $\Pi^{N}>\max \left[\Pi_{m}^{*}, \Pi^{M}, \Pi^{C}\right]$,

(ii) if $\mu \in\left[\mu_{1}(r), \mu_{2}(r)\right)$, then $\Pi^{M}>\max \left[\Pi_{m}^{*}, \Pi^{N}, \Pi^{C}\right]$,

(iii) if $\mu \in\left[\mu_{2}(r), \frac{3}{4}\right)$, then $\Pi^{C}>\max \left[\Pi_{m}^{*}, \Pi^{N}, \Pi^{M}\right]$,

(iv) if $\mu \in\left[\frac{3}{4}, 1\right]$, then $\Pi_{m}^{*}>\max \left[\Pi^{C}, \Pi^{N}, \Pi^{M}\right]$, with $r \equiv \frac{u_{l}}{u_{h}}, \mu_{1}(r) \equiv \frac{r(1-r)}{(6-r)}, \mu_{2}(r) \equiv \frac{2(1-r)}{6-r}$, and $0<\mu_{1}(r)<\mu_{2}(r)<\frac{3}{4}$. 


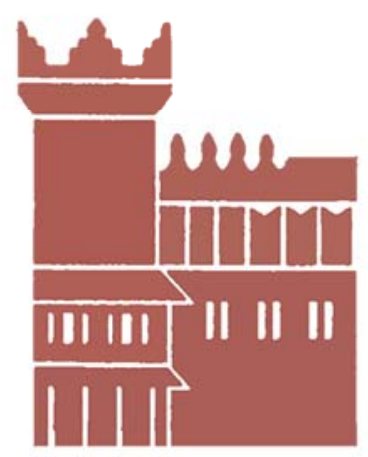

Alma Mater Studiorum - Università di Bologna DEPARTMENT OF ECONOMICS

Strada Maggiore 45

40125 Bologna - Italy

Tel. +39051 2092604

Fax +390512092664

http://www.dse.unibo.it 